\title{
Simple and accurate temperature correction for moisture pin calibrationsin oriented strand board
}

\author{
C.R. Boardman, General Engineer, Forest Products Laboratory ${ }^{1}$ \\ Samuel V. Glass, Research Physical Scientist, Forest Products Laboratory \\ Patricia K. Lebow, Mathematical Statistician, Forest Products Laboratory
}

Keywords:

moisture pin, Oriented Strand Board, moisture content, resistance, calibration, temperature

\begin{abstract}
Oriented strand board (OSB) is commonly used in the residential construction market in North America and its moisture-related durability is a critical consideration for building envelope design. Measurement of OSB moisture content (MC), a key determinant of durability, is often done using moisture pins and relies on a correlation between MC and the electrical resistance $(R)$ of the OSB between the pins. Early work on these correlations focused on solid lumber and recent correlations for engineered wood products lack data regarding the temperature effects on $\mathrm{R}$. We provide data on 1,001 resistance measurements in OSB, sourced from three different locations, over a wide temperature $\left(-17^{\circ} \mathrm{C}\right.$ to $\left.70^{\circ} \mathrm{C}\right)$ and relative humidity ( $35 \%$ to $95 \%$ ) range. This data, in conjunction with gravimetric $\mathrm{MC}$ readings, is used to test existing correlations and support a new simple, accurate formula for calculating MC from resistance and temperature measurements in OSB.
\end{abstract}

\footnotetext{
${ }^{1}$ Forest Products Laboratory, U.S. Forest Service, 1 Gifford Pinchot Dr., Madison, WI 53726

Corresponding author E-mail address: cboardman@fs.fed.us (C.R. Boardman); Tel. +1-608-231-9227
} 


\section{Introduction}

Oriented strand board (OSB)structural panel sheathing has been used in theNorth American residential construction market for several decades (see Zerbe [1] for a history of development).OSB has moisture transfer properties that differ from both plywood and construction lumber [2-3]. Moisturerelated durability is a critical consideration in building envelope design, particularly when insulation levels and airtightness of wall and roof assemblies are increased or new materials are introduced.Over the last 15 years a large number of field studies in various North American climates have monitored the hygrothermal performance of wall and roof assemblies that include OSB sheathing [4-24]. The moisture content $(\mathrm{MC})$ of OSB sheathing is a key criterion for evaluation of field moisture performance.Moisture accumulation in wood-based materials can lead to mold growth, fungal decay, corrosion of embedded metal fasteners, expansion-contraction damage, and loss of structural capacity. Development of mathematical models for some of these damage functions is the subject of ongoing research [25-35]. While mold growth depends on surface water activity (rather than bulk moisture content, though these are related), the other types of damage are dependent on moisture content. For example a common rule of thumb suggests keeping wood products below $20 \% \mathrm{MC}$ to minimize risk of decay [36-38]. In addition, questions about moisture risk have driven the ongoing interest in validation and tuning of hygrothermal modelsas well as parametric analysis [39-48] which allow the prediction of OSB moisture performance duringthe design ofbuilding envelope assemblies. Verification of the models depends on accurate measurement of $\mathrm{MC}$ in field and laboratory studies to compare to model prediction.

A common method for measuring moisture content of wood products in the field is through use of a moisture meter, which allows immediate spot readings, or installation of moisture pins with a data acquisition system for long term monitoring. Other researchers rely on direct gravimetric measurement which requires obtaining the mass of a wood sample before and after oven drying. Direct measurement, however, can be cumbersome in practice when applied to field experiments as it relies on either cutting out a specimen or inserting and removing a wood plug from a location in the assembly that may not be readily accessible [49]. While highly accurate, the method is labor intensive and may limit the frequency and extent of data collection. But it does find use in laboratory studies such as[50] which also illustrates the use of OSB outside the North American context as an interior vapor retarder. So while direct gravimetric measurement has its place, and OSB can be used for applications besides exterior sheathing, our work seeks to improve the practice of using moisture pins to measure MC in OSB commonly used as exterior sheathing where the risk of moisture accumulation is elevated (relative to interior use). A number of excellent guides to these field measurements are available [51-52]. These systems measure the resistance $(\mathrm{R})$ between the two pinsfastened into the wood and assume a correlation between the resistance and the MC. That correlation, and the variability of wood itself, makes this method inherently less accurate than a direct gravimetric measurement of the MC. Early work by William James identified the many factors that influence moisture meter readout [53], and he presented a table with resistance at various MC pointsfor a variety of wood species [54]. That basic 
correlation for Douglas-fir, which is shown in Figure 1, provided the foundation for much current work

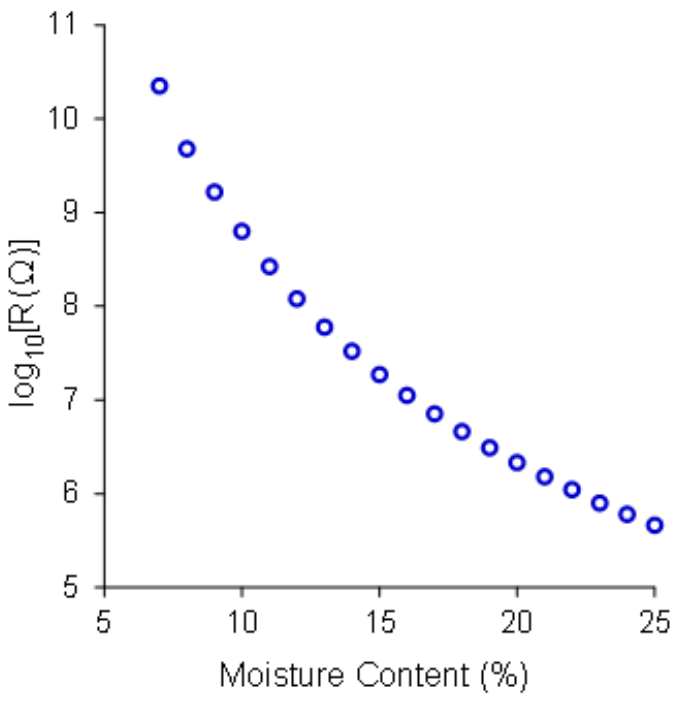

and many commercial moisture meters.

Figure 1 Resistance vs moisture content in Douglas-fir at $27^{\circ} \mathrm{C}\left(80^{\circ} \mathrm{F}\right)$.

The correlation for Douglas-fir at $27^{\circ} \mathrm{C}\left(80^{\circ} \mathrm{F}\right)$ can be expressed ${ }^{2}$ as:

$\log _{10}(M C)=2.971-2.086 \log _{10}\left[\log _{10}(R)\right]$

This correlation, like much of the work on moisture meters, is valid near room temperature. When moisture meter users want to find $M C$ at different temperatures a correction is applied, which is often based on the extensive work of Pfaff and Garrahan extending the original work by James[55-57]. Their correction factors for species and temperature include a large number of wood species but did not cover engineered wood like OSB.Dissatisfaction with thecomplicatedform of the Garrahan temperature correction, along with the two step nature of the calculation, was a significant motivation for undertaking our study. We want a simple and direct correlation that always includes temperature. There has not been enough attention paid to the temperature effects on moisture meters and very little published data exists supporting the temperature correction factors in engineered wood products. For example, moisture meter correction factors for untreated and ACQ treated plywood were provided by Boardman et al. [58]but did not include temperature compensation. Correction factors for OSB by Carll et al. [5] and Maref et al. [59] similarly were developed only at room temperature.

The lack of temperature correction factorsfor moisture content of engineered wood products introduces an unquantified measurement uncertainty in field investigation of new assemblies. Temperature correction can be particularly important for wall sheathing in cold climates and roof sheathing in any climate. The observation that the electrical conductivity of wood increases with increasing temperature has been known for over 50 years[53]. Further this suggests "that in wood the mechanism of conduction is by charge carriers whose number or mobility is increased by thermal

\footnotetext{
${ }^{2}$ This fit minimizes the error in prediction for MC based on James' data [54] and differs slightly from the fit provided by Straube et al. [52] which apparently minimized the error in $\log _{10}(\mathrm{MC})$.
} 
activity"[53]. Recent work by Zelinka et al. [60]advanced understanding of electrical conductance of wood though a percolation model that explains conductivity due to water pathways when the $\mathrm{MC}$ is $16 \%$ or more. Below the percolation threshold the conduction mechanisms are still not clear,and empirical models that reflect diffusion theory and Arrhenius equations provide some guidance on how the conductance responds to temperature (pg. 175 Hummel [61], see also [62-63]). Given this background, further work on temperature correction is warranted, especially for engineered wood products.

The present study is part of a larger effort to understand the effects of external insulation on OSB drying in a variety of test walls. To get accurate measurement of the MC of the OSB we compiled a number of OSB moisture pin correlations recently in use, including the method used by the moisture pin equipment manufacturer. Figure 2 presents these OSB correlations at room temperature, along with James'Douglas-fir data for reference[54].Although the correlations all indicate that OSB is more conductive than Douglas-fir lumber, they differ considerably when used to predict OSB moisture content. For example, a resistance reading of $1 \mathrm{M} \Omega\left(10^{6} \Omega\right)$ would yield an OSB moisture content ofabout $17 \%$ using one correlation butabout $21 \%$ using another correlation. The reasons for this large variation are not clear. The form of the correlation may not reflect well the underlying physics, or the fit may have been taken on too few samples, or the samples themselves may have differed because of different OSB manufacturing techniques and wood species used. We set out to improve on these existing correlationswhile also establishing a better understanding of how OSB sourced from different locations affects MC. The individual calculation methods and temperature corrections will be discussed below and evaluated against a set of OSB resistance data at representative MCs and temperatures. We also provide a new correlation and describe its advantages over other calculation methods. Finally, the data set was extended to cover OSB from different parts of North America to see the variation in OSB resistance regionally as different local tree species were used. Thisgives an initial indication of how much error one can expect from using a generic OSB correlation, compared to creating correlations specific to particular batches of OSB that might be used in one project. Of course more work needs to be done with OSB from other manufacturing locations to solidify a generic OSB correlation and the highest accuracy will generally result from testing individual OSB batches. We encourage further work evaluating OSB material variation and adoption of new correlation equation forms that are simple and accurate. 


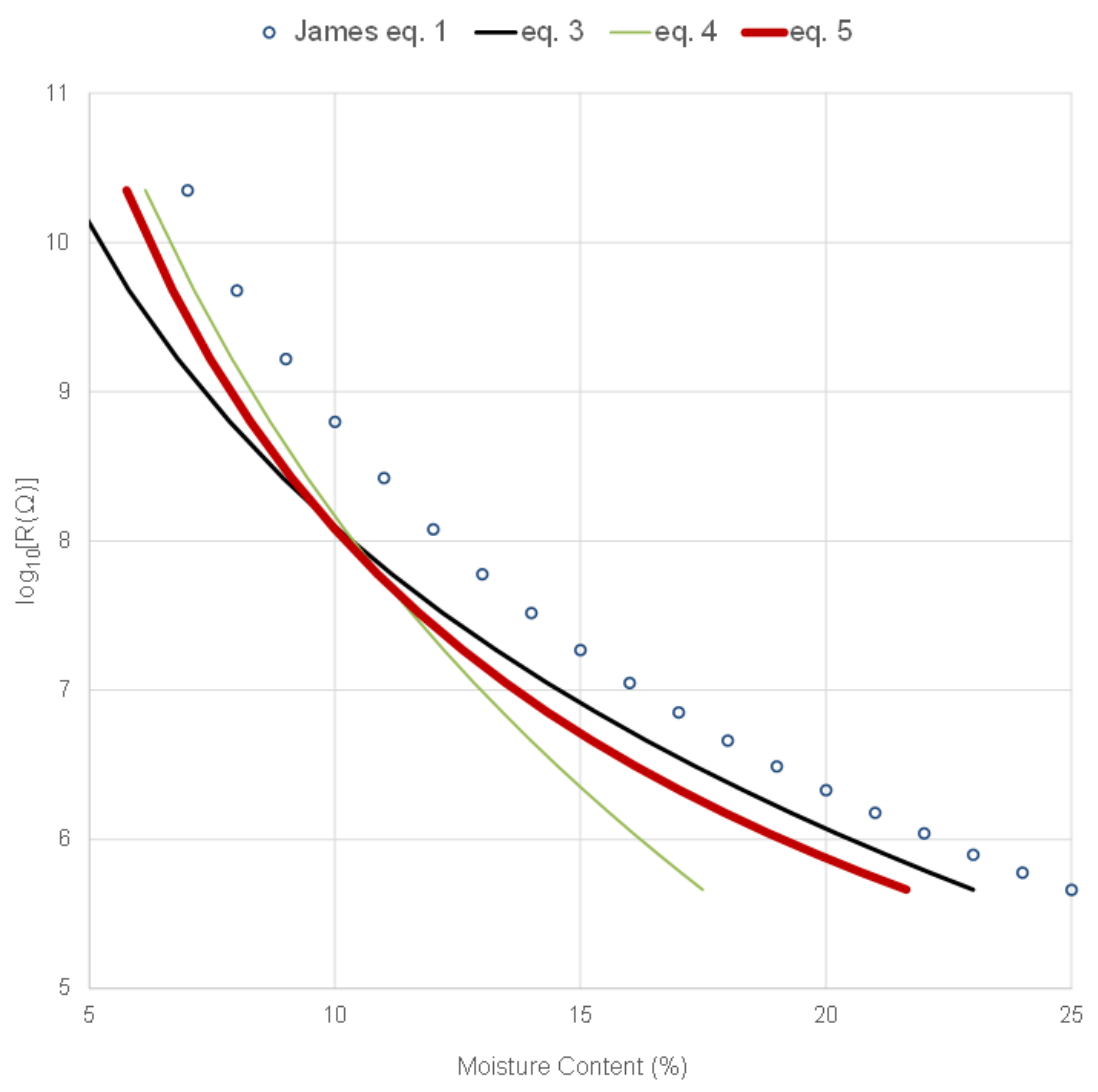

Figure 2 Resistance vs moisture content given different correlations for OSB, with Douglas-fir reference[54].

\section{Materials and Methods}

\subsection{Primary specimens}

All the samples for the primary data set were cut from the same $1.2 \mathrm{~m} \times 2.4 \mathrm{~m} \times 11 \mathrm{~mm}$ (nominal $\left.7 / 16^{\prime \prime}\right)$ thick OSB panel manufactured at a commercial mill in Michigan and obtained from a local building supplier.This OSB included wood from a mixture of tree species, primarily aspen (Populus), with some spruce (Picea), pine (Pinus), and a trace of basswood (Tilia). It had an oven-dry density of534 \pm $10 \mathrm{~kg} / \mathrm{m}^{3}$. Fifteen replicates each nominally $100 \mathrm{~mm} \times 100 \mathrm{~mm}$ were placed in six different relative humidity $(\mathrm{RH})$ chambers and left for over one month to condition to their equilibrium MC. Table 1 lists the conditions of each sample set. Two of the temperatures in that table, those at $26.6^{\circ} \mathrm{C}$, were not easily changed as these chambers were large conditioning rooms with a fixed temperature and $\mathrm{RH}$ used by multiple researchers. The goal was to reach different $\mathrm{MC}$ conditions in each sample set so a large range of resistance readings could be obtained, not to create a sorption isotherm. An additional twelve samples were first water soaked ${ }^{3}$, allowed to dry in a $50 \% \mathrm{RH}$ room, and then sixcontinued to conditionin the $50 \% \mathrm{RH}$ room while the other six were placed in an $88 \% \mathrm{RH}$ chamber. These samples

\footnotetext{
${ }^{3}$ Similar to the procedure for any aqueous wood preservative treatment but here with water only, as used in Boardman et al. [42], the samples were placed in vacuum at $20 \mathrm{kPa}$ for 30 minutes followed by pressurization with water at $1034 \mathrm{kPa}$ for 60 minutes.
} 
allowed comparison to the standard boards which all started their conditioning around $50 \% \mathrm{RH}$ without being water soaked. Finally, an additional 10 specimens were conditioned at $60{ }^{\circ} \mathrm{C}$ and $80 \% \mathrm{RH}$. This supplemental data set allowed verification that the resistance temperature relationship explored below was not influenced by how the equilibrium MC conditions were achieved.

Table 1 OSB sample conditions

\begin{tabular}{|l|l|}
\hline RH (\%) & Temperature \\
\hline 35 & $26.6^{\circ} \mathrm{C}$ \\
\hline 50 & $23^{\circ} \mathrm{C}$ \\
\hline 65 & $26.6^{\circ} \mathrm{C}$ \\
\hline 75 & $23^{\circ} \mathrm{C}$ \\
\hline 88 & $23^{\circ} \mathrm{C}$ \\
\hline 95 & $23^{\circ} \mathrm{C}$ \\
\hline
\end{tabular}

After reaching equilibrium $2.4 \mathrm{~mm}$ diameterholes were drilled using a standard jig with holes placed $31.8 \mathrm{~mm}$ on center. The electrodes placed into these holes were not standard moisture pins, but rather slotted hex washer head stainless steel 18-8 \#6 $\times 1 / 2$ " sheet metal screws, similar to those used in Boardman et al. [58]. Insulating washers were placed below the hexagonal screw heads and in contact with the OSB surface so only the screw threads contact the wood. Between the insulating washer and the screw head was an uninsulated ring terminal crimped and soldered to lead wires connected to circuitry used to take the electrical resistance measurements. See Figure 3 for a photograph of one specimen with screws and lead wires attached along with individual spare parts. When the screws were installed, a tight fit created electrical contact between the ring terminal and screw head. Note that this systemallows finding the most conductive path through the wood at any depth but our equilibrated samples should not have had any moisture gradients. After installation of the screws and lead wires the samples were double wrapped in plastic bags with the lead wires carefully threaded out to minimize moisture transfer into or out of the sample while allowing resistance measurements to be taken at a variety of temperatures. Sets of these wrapped samples were then placed in temperature and humidity controlled chambers with the lead wires exiting the chamber. Resistance readings were taken at temperatures of $-17,-5,5,23,40$, and $70^{\circ} \mathrm{C}$. Finally, the samples were removed from the plastic, screws removed, and a final mass check confirmed typically less than $0.2 \%$ mass change before and after resistance readings. 


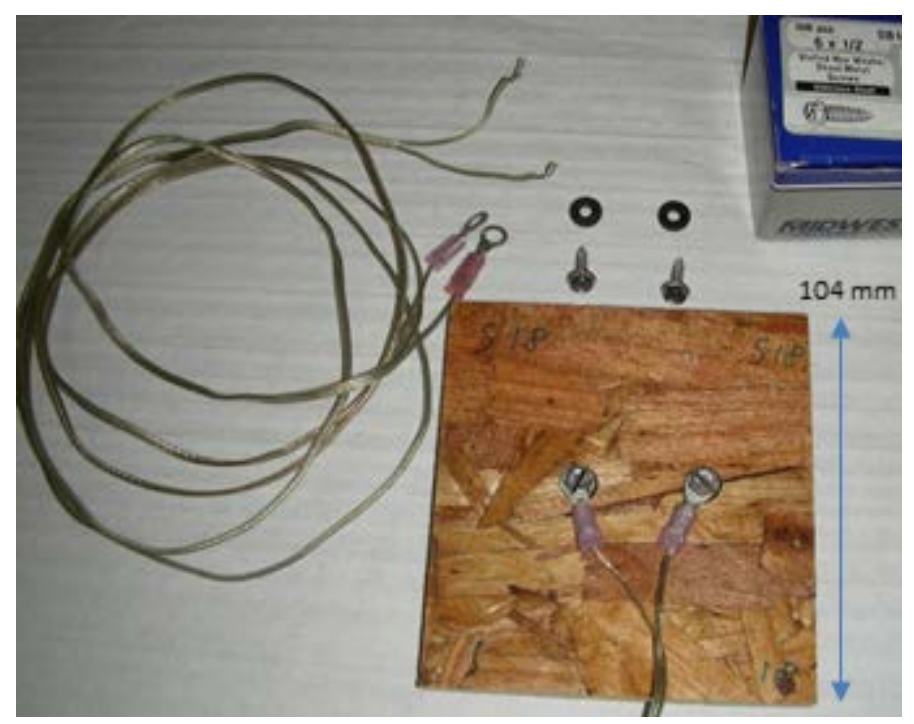

Figure 3Photograph of OSB specimen with screw and wire lead attachments

The resistance readings were taken with a voltage divider system capable of reading resistance up to $20 \mathrm{G} \Omega$ with less than $4 \%$ error, with a typical error of only $2 \%$ for lower resistances. A $10 \mathrm{~V}$ signal was applied to a circuit consisting of a reference resistor (from $200 \mathrm{k} \Omega$ to $10 \mathrm{M} \Omega$ ) in series with the specimen, with voltage read across the reference resistor and resistance calculated for the specimen by voltage division. This system was automated to take 4 sequential readings with polarity of the applied voltage reversed between readings and the final resistance calculated as an average of the total four.

Gravimetric wood moisture content was calculated in the usual manner as the difference between the conditioned mass and oven-dry mass, divided by oven-dry mass. All specimens were ovendried at $105^{\circ} \mathrm{C}$ after resistance measurements were complete. The oven-dry specimen was considered stable after 18 hours in the oven with a mass change between readings over 4 hours apart typically less than $0.1 \%$ mass change, with maximum $0.28 \%$.All specimens were weighed on a top loading balance with readability of $0.001 \mathrm{~g}$. This procedure is similar to the secondary standard for oven-drying outlined in ASTM D4442-15 [64] which gives as a guide that "constant mass" is typically obtained within 24 hours in the oven when no appreciable change is noted in final mass at approximately 4 hour intervals. In our case the typical change observed limits the MC accuracy to $0.2 \%$ and could not be improved without the much stricter mass measurement requirements in the primary standard.

\subsection{Secondary specimens}

Samples for the secondary data set were cut from $11 \mathrm{~mm}$ (nominal 7/16")OSB sourced from Texasand British Columbiamills. Texas OSB samples were made from primarily southern yellow pine wood, and had an oven-dry density of $564 \pm 19 \mathrm{~kg} / \mathrm{m}^{3}$. British Columbia OSB samples were made from primarilyaspen wood (Populus), and had an oven-dry density of $565 \pm 49 \mathrm{~kg} / \mathrm{m}^{3}$. Six replicates from each location were placed in the same conditions as Table 1 and prepared for resistance readings in the same manner as the primary data set. The temperatures sampled included $-17,-5,5,10,23,40$, and $60^{\circ} \mathrm{C}$. The $10{ }^{\circ} \mathrm{C}$ reading was added to be the lower temperature reading for the $50 \% \mathrm{RH}$ readings. Very dry and cold samples reach resistance values too high for our equipment to measure reliably. The high 
temperature was reduced from 70 to $60^{\circ} \mathrm{C}$ to improve the accuracy of MC estimate at high temperatures. When samples conditioned to high moisture content are raised to $70{ }^{\circ} \mathrm{C}$ a small amount of water leaves the sample and collects in the plastic bag, introducing an uncertainty in the actual MC of the sample. The reduced MC for some of the primary samples was estimated by comparing the initial and final mass of the sample after all temperature changes were completed. Reducing the maximum temperature to $60^{\circ} \mathrm{C}$ eliminated this problem for the secondary data set.In the primary data set the MC at $70^{\circ} \mathrm{C}$ was estimated as slightly below that of the other temperatures for select samples due to this issue, as shown the Appendix Table A.1 column for $\mathrm{MC}(\%)$ at $70^{\circ} \mathrm{C}$.Otherwise the same procedures as the primary data set were used to measure resistance and final oven-dry mass.

\subsection{Data analysis methods}

Trends in the data were investigated in multiple ways. Linear and nonlinear models were used to understand the trends in the underlying data. Trend models in Table 2 were fit with a SAS ${ }^{\circledR}$ V9.4 [65] mixed model procedure (glimmix) to accommodate two sources of random variation (within and between specimens). Primary model fitting for the calibration equation is based on nonlinear inverse regressions to optimally predict moisture content. These fits were obtained with Microsoft Excel ${ }^{\circledR}$ Solver (GRG) with reduced weighting given to a few of the primary data sets to improve prediction. The squared residualsfrom $-17{ }^{\circ} \mathrm{C}$ at $65 \% \mathrm{RH},-5^{\circ} \mathrm{C}$ at $50 \% \mathrm{RH}$, and $5{ }^{\circ} \mathrm{C}$ at $30 \% \mathrm{RH}$ wereweighted by $50 \%$ to account for uncertainty in this data as resistances were very large. Overall model fits are based on comparisons of root-mean-square-error (RMSE) and visual assessments of the residuals. An equal weighted model was also fit for comparison of parameter estimates and calculation of the parameter estimates approximate standard errors (SE). It was fit with both the Excel solver and with the default Gauss-Newton nonlinear fitting routine in R[66]. 


\section{Results}

\subsection{Basic trends}

The basic trends are shown first for room temperature measurements. Figure 4a indicates that OSB had a lower resistance than Douglas-fir at the same MC.

(a)
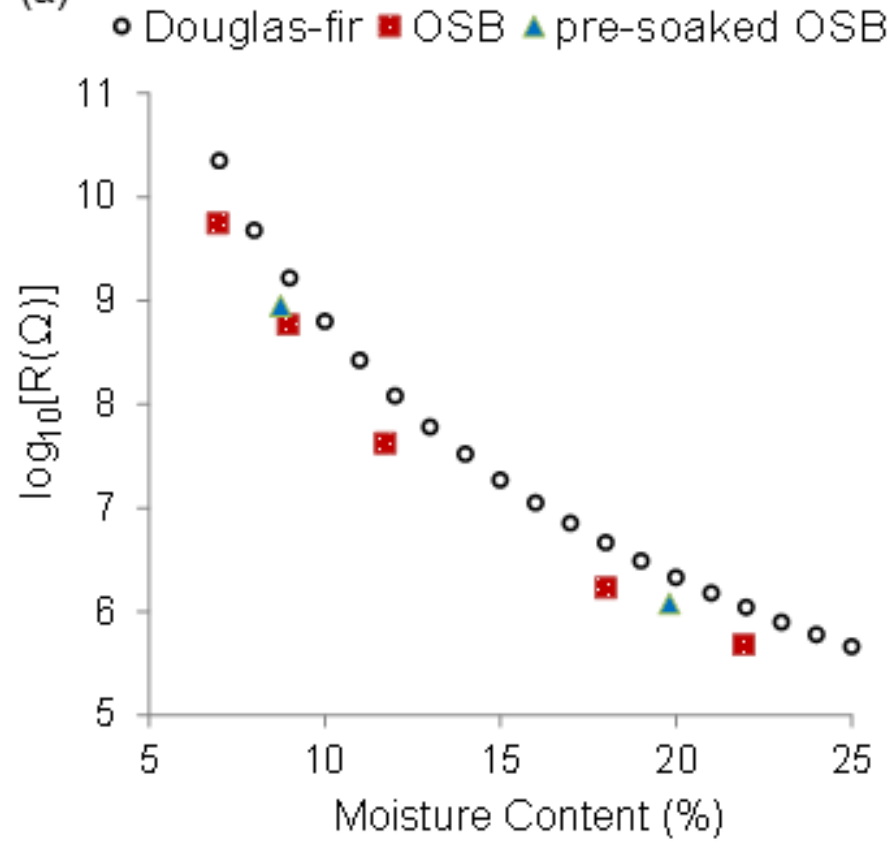

(b)

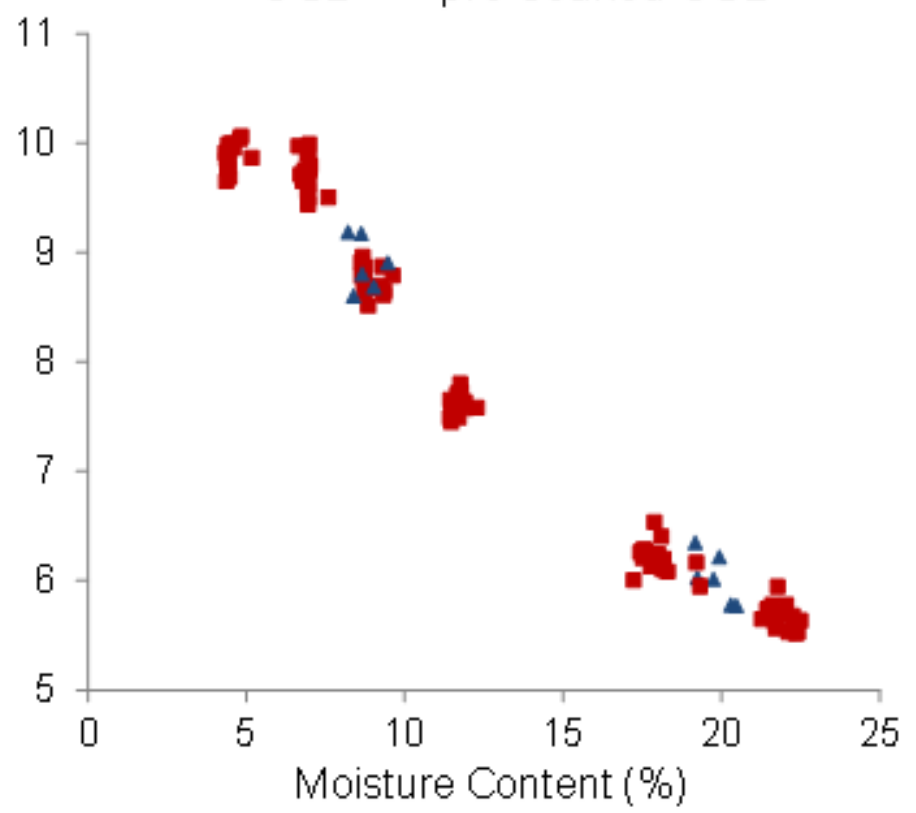

Figure 4a) OSB Resistance versus moisture content at room temperature, with Douglas-fir reference[54]. Each point for OSB represents the average of a group of specimens conditioned at a given relative humidity level. b) Resistance versus moisture content for all primary OSB samples at room temperature

This is similar to plywood[58] and, again, suggests that the glue used in engineered wood products is more conductive than the wood, indicating that a different $M C$ versus $R$ correlation is needed. Figure $4 \mathrm{~b}$ presents all the primary OSB data points at room temperature to show the typical variations in reading.Unlike plywood, which had a higher resistance after water treatment and conditioning to a given moisture content, there was no significant difference in $M C / R$ relationship between the pre-soaked samples and the standard OSB, despite the irreversible thickness swelling that occurs when OSB gets wet. The pre-soaked specimens reached higher equilibrium moisture content(EMC) than the non-soaked specimens conditioned at the same relative humidity, which is probably a result of sorption hysteresis. This does not matter to the results because resistance is correlated with MC rather than RH.

Similarly, the regional differences in OSB production due to different wood species had little effect on the resistance but changed the equilibrium $M C$ somewhat. These trends are indicated in Figures 5-7where TX indicates OSB from Texas and BC indicates OSB from British Columbia while MI indicates the primary data set from Michigan.Figure 5 is a summary of our resistance versus moisture content data for all three regions. Figure 6 provides reference data from previous investigations of the sorption and desorption EMC for OSB [67-75], along with best fit curves to each set. This compilation of literature data indicates that the hygroscopicity of OSB can vary considerably, since the moisture 
sorption isotherms show considerable variation in equilibrium $\mathrm{MC}$ at given RH.Figure 7 plots our summary data from the three regions over the fits of EMC versus RH from the reference data. The direction of sorption (adsorption vs. desorption) in our measurements was not strictly controlled; specimens were placed in various $\mathrm{RH}$ conditions as received and prior history was not known. Again, the goal of this work was to enhance the understanding of temperature effects on resistance readings across a range of $\mathrm{MC}$ values, not to investigate the sorption isotherm. Our EMC values generally fall between the reference adsorption and desorption curves, with OSB from the Texas mill typically having higher EMC than OSB from the Michigan and British Columbia mills. The reference figures and comparison to our data were provided to show that our three different sample locations have EMC behavior similar to previous investigations.

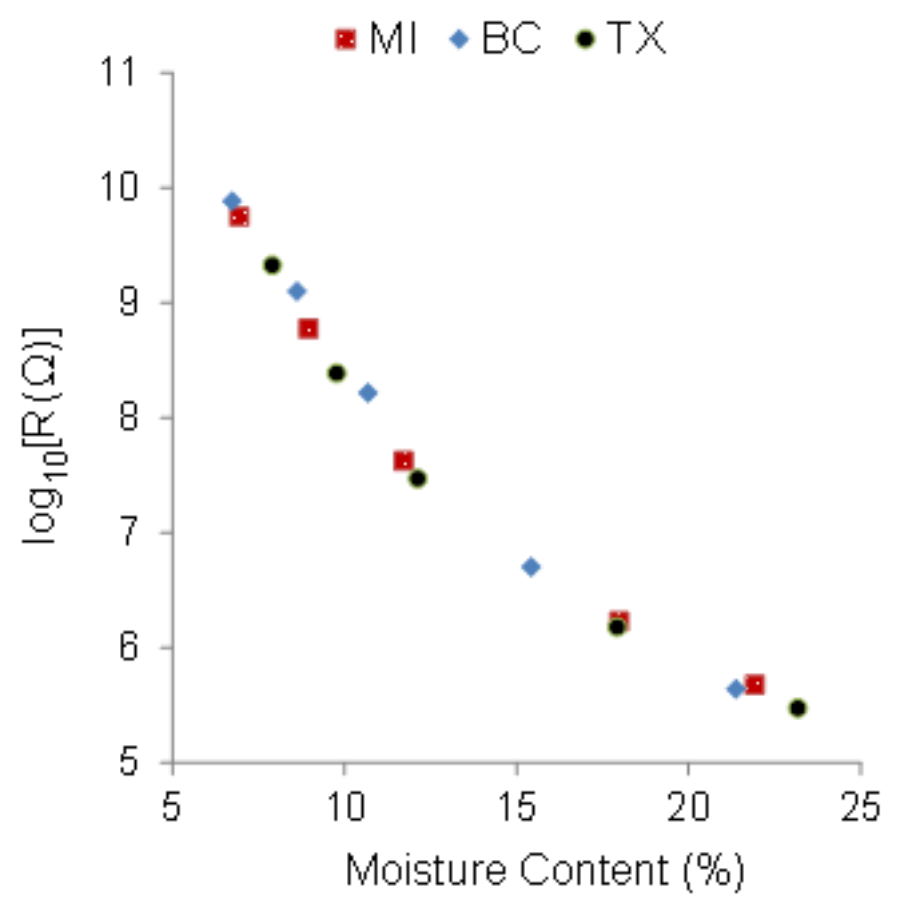

Figure 5 Resistance versus moisture content for different sources of OSB 

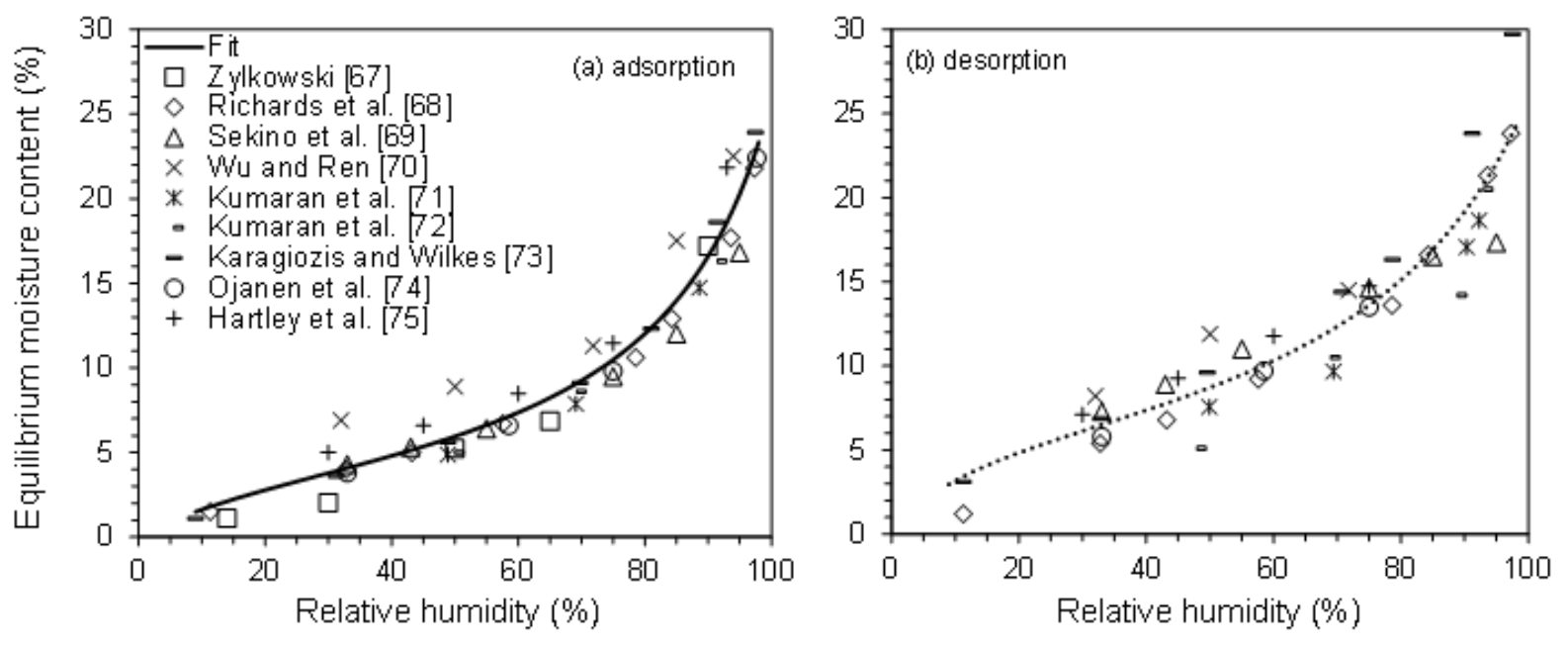

Figure 6 OSB adsorption (a) and desorption (b) data from literature along with best fit curves.

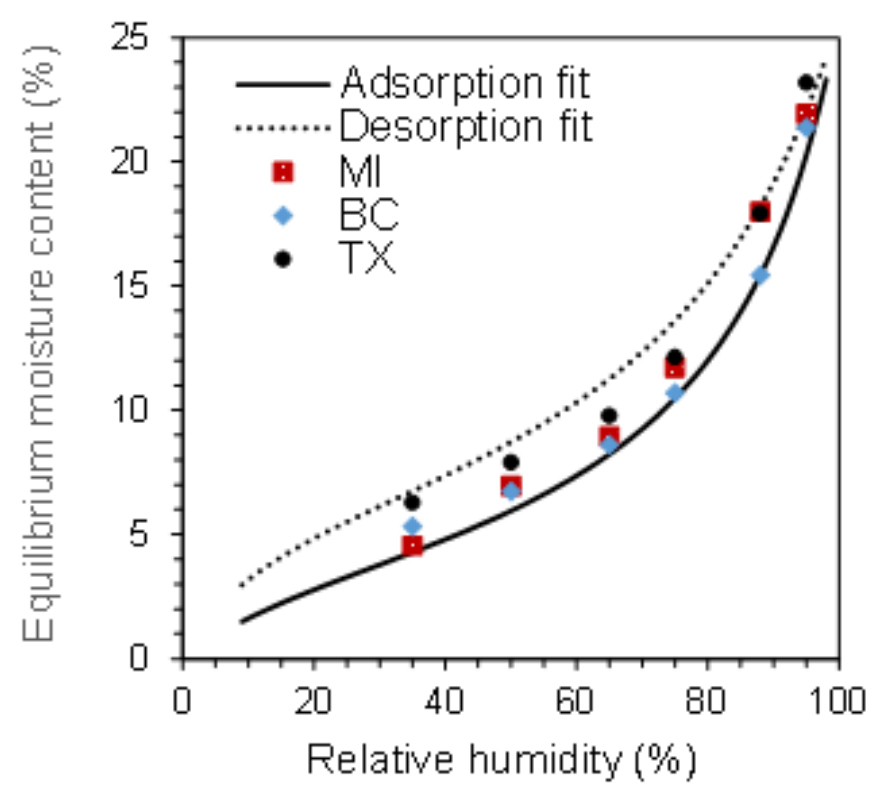

Figure 7 Moisture Content versus relative humidity for different sources of OSB 


\subsection{Temperature effects}

The results become more complicated when temperature effects are included. Figure 8is a plot of the logarithm of resistance versus inverse temperature.It shows the resistance decreased as the temperature increased, but the temperature is plotted as 1000 divided by the temperature in Kelvin to create an upward sloping set of graphs at constant MC. EMC is indicated in the legend on top, and linear fit lines are applied to the data points to indicate overall trends.
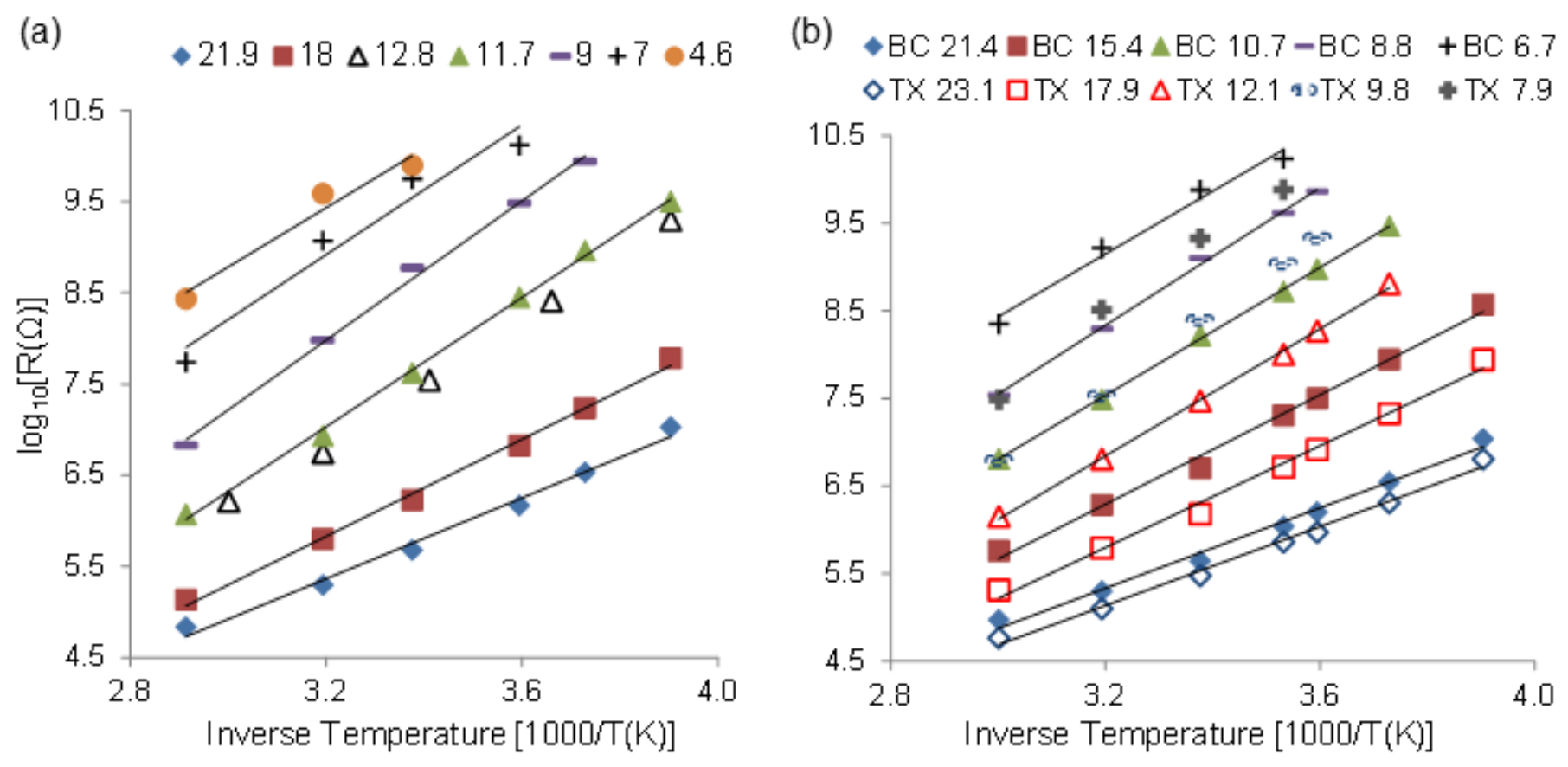

Figure $80 S B \log _{10}$ R versus $1000 /$ temperature. a) MI Primary set, b) BC and TX secondary set.

Figure $8 \mathrm{a}$ includes the average resistance of the additional 10 specimens in the supplemental set conditioned at $60{ }^{\circ} \mathrm{C}$ and $80 \% \mathrm{RH}$, which are indicated by the open black triangles at $12.8 \% \mathrm{MC}$ and behave similarly to the $11.7 \% \mathrm{MC}$ of the standard $75 \% \mathrm{RH}$ samples. Figure $8 \mathrm{~b}$ presents the secondary data sets and indicates the temperature trends are not significantly different from the primary set. Note that, while a linear fit appears to work well, the slopes are different for different MCs based on a multilevel linear model of the sets of the specimens (excluding some observations where measured resistance had a large uncertainty). Each separate location (MI, BC, TX) was treated as a set with one common non-zero intercept and then the slope was determined for each subset of MCs. The hypothesis that the MC slopes were identical within each separate location was rejected $(p<0.0001)$. Although the models allow correlation within each specimen, the residuals indicate some nonlinearities not accommodated by the simple models. The data in Figure 8 appear nonlinear with downward curvature at low moisture content but with upward curvature at high moisture content. Table 2 presents the slopes of linear fits, with common non-zero intercept within each group, to data in Figure 8showing increasing slope with decreasing MC.Precision estimates for the slope coefficients are given in Table 2 by the standard errors (SE); they are derived as a function of both the between and within specimen errors 
within each group. The nonzero intercepts are estimated as -3.12 with standard error (SE) $=0.081$ for $\mathrm{MI}$, -3.23 with $\mathrm{SE}=0.107$ for $\mathrm{BC}$, and -3.89 with $\mathrm{SE}=0.142$ for $\mathrm{TX}$. The full data set of resistance and temperature measurements for all samples is provided in Appendix $A$.

Table 2 Slope for $\log _{10} R$ vs Inverse Temperature (1000/K) in Figure 8

\begin{tabular}{|c|ccc|}
\hline Origin & $\begin{array}{l}\text { Moisture } \\
\text { content (\%) }\end{array}$ & slope & $\pm S E$ \\
\hline MI & $\mathbf{2 1 . 9}$ & 2.61 & 0.025 \\
& 18 & 2.78 & 0.025 \\
& 12.8 & 3.13 & 0.026 \\
& 11.7 & 3.20 & 0.025 \\
& 9 & 3.48 & 0.026 \\
& $\mathbf{9}$ & 3.75 & 0.026 \\
& $\mathbf{9 . 6}$ & 3.93 & 0.028 \\
BC & & & \\
& $\mathbf{2 1 . 4}$ & 2.64 & 0.032 \\
& $\mathbf{1 5 . 4}$ & 2.99 & 0.032 \\
& $\mathbf{1 0 . 7}$ & 3.38 & 0.033 \\
& $\mathbf{8 . 8}$ & 3.63 & 0.033 \\
& $\mathbf{6 . 7}$ & 3.86 & 0.034 \\
& & & \\
& $\mathbf{2 3 . 1}$ & 2.77 & 0.043 \\
& $\mathbf{1 7 . 9}$ & 3.01 & 0.043 \\
& $\mathbf{1 2 . 1}$ & 3.37 & 0.045 \\
& $\mathbf{9 . 8}$ & 3.63 & 0.045 \\
& $\mathbf{7 . 9}$ & 3.87 & 0.046 \\
\hline
\end{tabular}

\subsection{Calibration equation}

Our primary interest was in creating a correlation that allowed calculation of $\mathrm{MC}$ from resistance and temperature data in OSB. See equation 2 for our preferred form where $b_{x}$ are fit coefficients, $\mathrm{T}_{\mathrm{f}}$ represents 1000 divided by temperature in Kelvin, and $\mathrm{R}$ is the resistance in ohms.

$M C=b_{0}+b_{1} T_{f}^{b_{4}}+b_{3} T_{f}^{b_{4}} \log _{10}\left[\log _{10}(R)-b_{2}\right]$ 
The form of this equation was chosen for simplicity and ease of calculation, just including the terms that help to create a good correlation with a small nod to the underlying physics which is hinted at in the use of the inverse temperature and the log function commonly used in these correlations. We provide all our data in case someone wants to try a more complex calculation that better reflects the underlying physics. As discussed below other correlations also work satisfactorily, but are unnecessarily complicated. For this equation form a global optimizationacross both the primary and secondary data sets, including the pre-soaked samples, yields fit coefficients $b_{0}=-8.6810, b_{1}=3.7172, b_{2}=3.8974, b_{3}=-$ $2.9129, b_{4}=1.9000$. This results in an overall root-mean-square-error (RMSE) of 0.726 in \%MC for MC

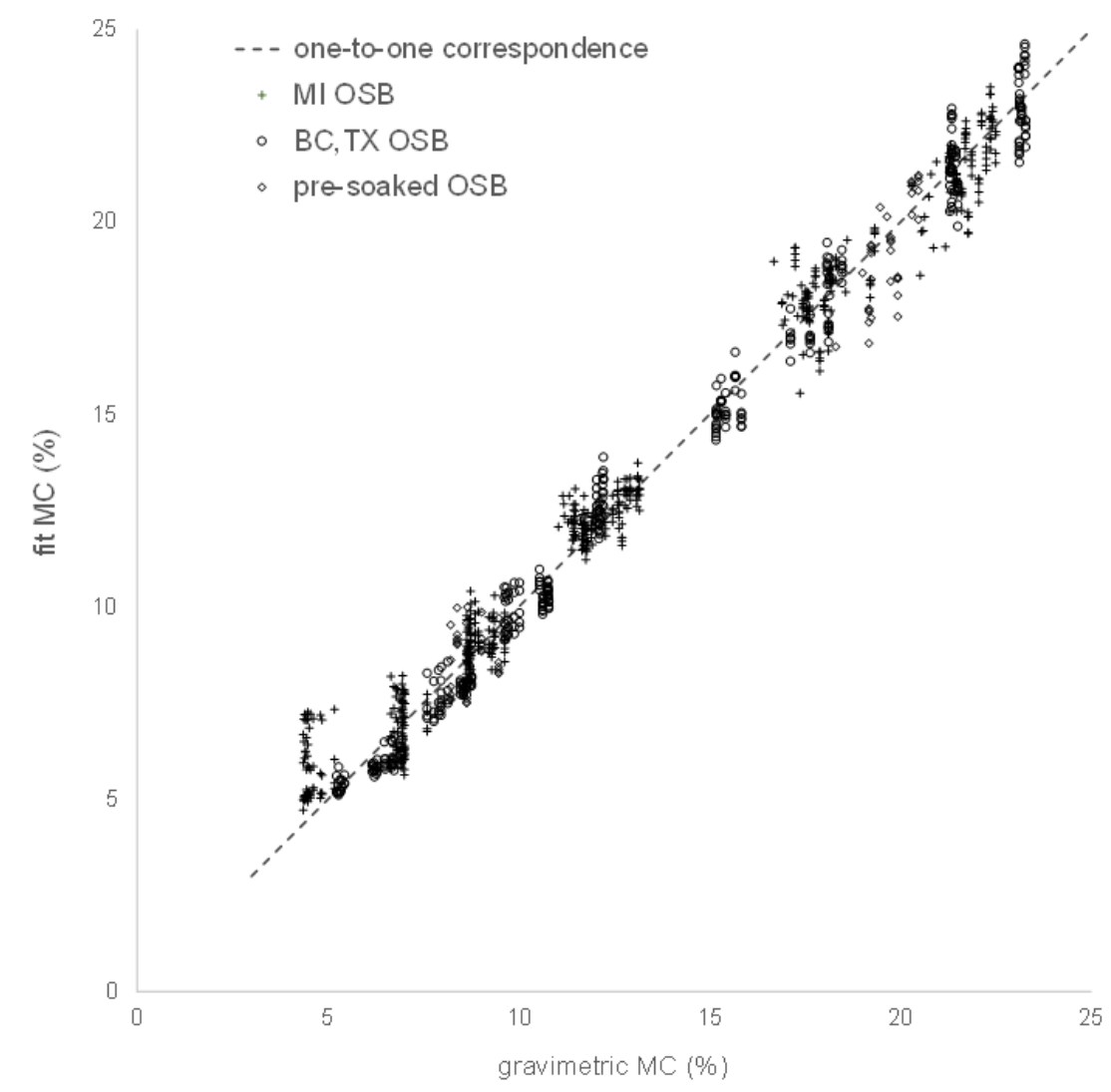

Figure 9 Eq. 2 correlation fit moisture content versus gravimetric moisture content for all data 
across the total sample size of 1001 measurements. Figure 9shows the fit MC versus the gravimetric MC for this correlation for all 1001 data points. Figure 10 presents a different view of the data scatter by plotting resistance versus moisture content comparing the fit from equation 2 to the gravimetric MC at three different temperatures.

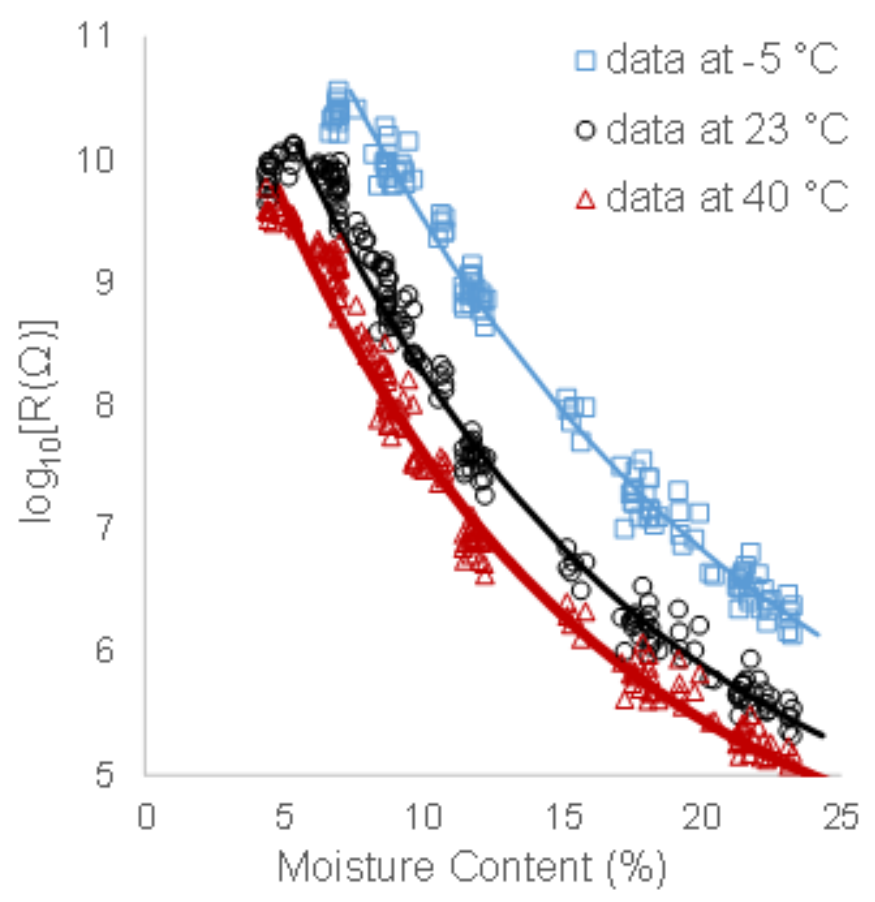

Figure 10 Resistance versus gravimetric moisture content at three temperatures showing curve fits (Eq. 2)

Another indication that this correlation is robust can be seen in Table 3 which shows the optimized fit coefficients for each of four subsets of the data, along with two versions of the RMSE, one using the subset optimized fit and the other using the overall fit. The first row indicates the overall fit from the full data set. The subsequent rows fit the Primary set (MI), just the water-soaked (pre-soak), the British Columbia set (BC) and the Texas set (TX).The final lines in Table 3 show fit coefficients and their associated approximate standard errors using the R statistical software package to optimize equation 2 on an equally weighted data set. Small standard errors relative to the coefficient estimates are indicative of more precise parameter estimates. Recall that the other correlation parameters reduce the weight of select data sets with high resistance as described in the data analysis methods section above. By going to a combined five-parameter model, versus separate models for each group, the subsets experience modest increases in their RMSE with the exception of the BC subset, which experiences a $35 \%$ increase in RMSE under the overall fit. Although statistically significant, it still does not exceed the error within each of the other subsets. 
Table 3 Fit coefficients and RMSE for various data subsets

\begin{tabular}{|l|r|r|r|r|r|r|r|r|}
\hline Data & \multicolumn{1}{|c|}{$n$} & overall RMSE & subset optimized & $b 0$ & $b 1$ & $b 2$ & \multicolumn{1}{l|}{$b 3$} & \multicolumn{1}{l|}{$b 4$} \\
\hline Full & 1001 & 0.726 & & $-\mathbf{- 8 . 6 8 1 0}$ & $\mathbf{3 . 7 1 7 2}$ & $\mathbf{3 . 8 9 7 4}$ & $\mathbf{- 2 . 9 1 2 9}$ & $\mathbf{1 . 9 0 0 0}$ \\
\hline MI & 545 & 0.754 & 0.731 & -8.7427 & 3.5252 & 3.9101 & -2.7992 & 1.9465 \\
\hline pre-soak & 72 & 0.949 & 0.804 & -38.6449 & 39.2631 & 1.1845 & -22.7684 & 0.7433 \\
\hline BC & 192 & 0.601 & 0.445 & -16.6093 & 9.3989 & 3.7188 & -6.0133 & 1.3177 \\
\hline TX & 192 & 0.661 & 0.612 & -7.5852 & 2.7011 & 4.1152 & -2.0905 & 2.0789 \\
\hline equal weight & 0.765 & & -7.6192 & 3.2420 & 3.8947 & -2.6262 & 1.9913 \\
\hline standard error & & & 0.8252 & 0.4271 & 0.0569 & 0.2989 & 0.0799 \\
\hline
\end{tabular}

\subsection{Comparison to previous correlations}

In this section we show the results of running three different previously used OSB correlations against our full data set, both as given and as optimized for this data set. This state of the art survey suggests the need for a simplified equation form like equation 2 . The calculation formulas shown below were modified to include 5 optimization coefficients, to allow a fair comparison to equation 2 . In each case these equations use the temperature in ${ }^{\circ} \mathrm{C}$, represented as $\mathrm{T}$. They also often use the natural log, denoted by $\ln ()$, or e raised to a power, denoted by $\exp ()$. The first case is that outlined by a manufacturer of moisture pins and data acquisition equipment (private communication), which uses formulas from both Maref[59] and Garrahan[56] in a string of calculations shown as equation 3.

$$
\begin{aligned}
& M C_{u}=\exp \left[b_{0}-b_{1} \ln (R / 1000)\right] \\
& M C_{t}=\frac{M C_{u}+0.567-0.026 T+0.000051 T^{2}}{0.881 \times 1.0056^{T}}-b_{2} \\
& M C=100 \times \exp \left[b_{3} \ln \left(M C_{t} / 100\right)+0.001187 b_{4}\right]
\end{aligned}
$$

As given $b_{0}=4.0954, b_{1}=0.14006$, and $b_{3}=1.055$ with the other fit coefficients not used $\left(b_{2}=0, b_{4}=1\right)$. This results in a RMSE of 1.7 on our data set. Our optimized fit using all fit coefficients improves the RMSE to 0.927 as shown in Table 4.

The second case is taken from a paper by Carll et al.[5] which makes only a modest effort to include the temperature effects by assuming a constant straight-line relationship between natural log of resistance and temperature. This is shown in equation 4.

$$
M C=\exp \left\{b_{0}+b_{1}\left[b_{3} \ln (R)-b_{2}\left(21+b_{4}-T\right)\right]\right\}
$$

As given $b_{0}=4.170, b_{1}=-0.097$, and $b_{2}=0.0792$ with other fit coefficients not used $\left(b_{3}=1, b_{4}=0\right)$. This results in a RMSE of 2.29 for our data set. Our optimized fit using all fit coefficients improves the RMSE to 1.04 as shown in Table 4.Finally the third case is taken from Straube's field guide[52] and is shown in equation 5 . 


$$
\begin{aligned}
& M C_{u}=10^{b_{0}-b_{1} \log _{10}\left[\log _{10}(R)-b_{2}\right]} \\
& M C=\left(\frac{M C_{u}+0.567-0.026 T+0.000051 T^{2}}{0.881 \times 1.0056^{T}}-b_{4}\right) / b_{3}
\end{aligned}
$$

As given $b_{0}=2.990, b_{1}=2.113, b_{2}=0$ is not used, $b_{3}=1.1114$, and $b_{4}=0.366$. This results in a RMSE of 1.52 for our data set. Our optimized fit using all fit coefficients improves the RMSE to 0.773 as shown in Table 4.

Table 4 Fit coefficients and RMSE for various calculation methods

\begin{tabular}{|l|r|r|r|r|r|r|r|}
\hline Method as given RMSE & optimized RMSE & $b 0$ & $b 1$ & $b 2$ & $b 3$ & $b 4$ \\
\hline Eq 2 & & 0.726 & -8.6810 & 3.7172 & 3.8974 & -2.9129 & 1.9000 \\
\hline Eq 3 & & 0.927 & 3.8786 & 0.0893 & 5.6819 & 1.0176 & 1.0667 \\
\hline Eq 3 & 1.7 & & 4.0954 & 0.1401 & 0 & 1.0550 & 1 \\
\hline Eq 4 & & 1.04 & 4.8165 & -0.1349 & 0.0704 & 0.9543 & -2.8194 \\
\hline Eq 4 & 2.29 & & 4.1700 & -0.0970 & 0.0792 & 1 & 0 \\
\hline Eq 5 & & 0.773 & 2.5607 & 1.3322 & 0.0000 & 1.1935 & 9.8660 \\
\hline Eq 5 & 1.52 & & 2.9900 & 2.1130 & 0 & 1.1114 & 0.3660 \\
\hline
\end{tabular}

Figure 11 plots the optimized fit for each equation against the data for two temperatures, similar to Figures 2 and 10, to illustrate the improvement provided by equation 2 . 


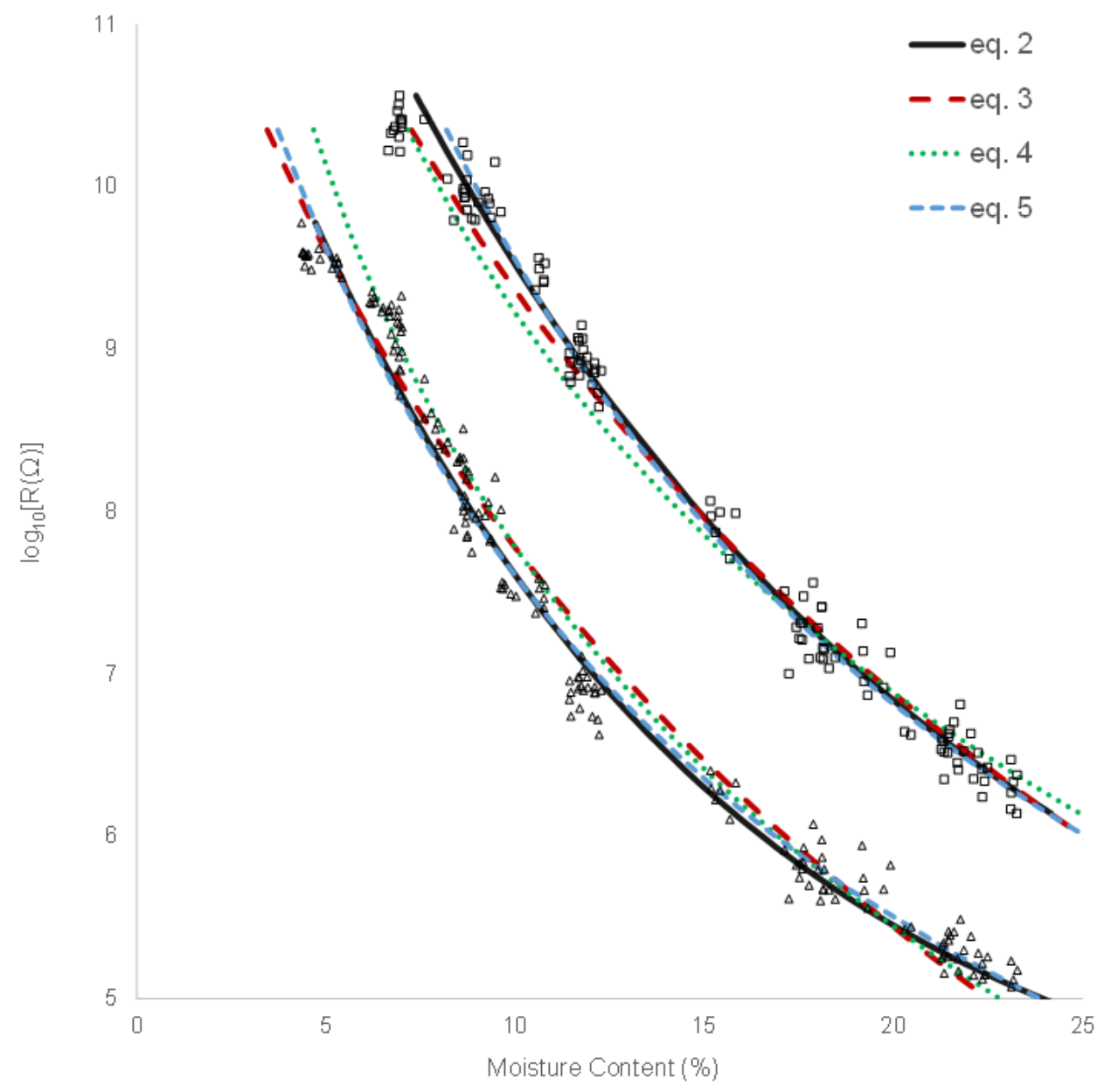

Figure 11 Comparison of optimized correlations at $-5{ }^{\circ} \mathrm{C}$ (upper set) and $40{ }^{\circ} \mathrm{C}$ (lower set).

\section{Discussion}

Clearly the influence of temperature on moisture pin resistance is significant and complex.

Figure 8 is similar to Arrhenius plots which typically show the effect of temperature on rates of chemical reactions, with the slope proportional to the activation energy for the reaction. A similar interpretation can be applied to our data: the activation barrier for charge carrier conduction(proportional to the slope) decreases as moisture content increases.Non-linearity was evident, however, in these Arrhenius plots, and curvature was in different directions at low and high moisture content. This may be an indication that different conduction mechanisms are at workin low and high moisture regimes.

In this work we publish all our OSB data and compare our suggested correlation to existing formulas to inspire further work. We suggest that building science researchers pay closer attention to the temperature correction, folding it into the base correlation that relates resistance to moisture content, not treating it as an afterthought. Many of the current correlations in use are overly complex, even if they are accurate enough for most purposes. Our suggested correlation (Eq. 2) has enough complexity that it can handle the wide temperature range we explored, yet can be written in one line. It 
uses the more fundamental absolute temperature in Kelvin thus avoiding negative numbers and allowing the fit to use fractional powers of the temperature. It also contains a cross term with both temperature and resistance, improving accuracy. It is suggested that future work include an even better mathematical form to capture the complex physics governing charge carriers in wood and wood composites. Meanwhile, equation 2 has reduced the RMSE compared to commonly used correlations.

Further evidence for the importance of temperature correction can be demonstrated by fittingequation 5 without the benefit of the full data set. Fitting all parameters to only the resistance data at room temperature yields an overall RMSE of $1.173\left(b_{0}=2.274, b_{1}=1.108, b_{2}=0\right.$ is not used, $b_{3}=0.822$, and $b_{4}=9.847$ ). The rest of the reduction to RMSE of 0.773 is only accomplished when using the full data set with temperature variations. This suggests that the temperature correction for OSB differs from that for solid wood, for which equation 5 was originally developed. Also note that the fit parameters that control temperature have moved considerably as $b_{4}$ changes from less than 1 as originally given to near 10 . One of the motivations for developing equation 2 was to allow a more robust calculation on diverse data sets.

The robustness of our preferred correlation has yet to be fully demonstrated, but the variability in the $\mathrm{MC} / \mathrm{T} / \mathrm{R}$ relationship for OSB panels from different geographic locations sampled in this study could be handled by a single calibration equation. The overall fit for the full data set resulted in a RMSE of less than $1 \%$ MC when applied to the full data set as well as all subsets, implying that variability across the panels from different mills was not appreciably greater than within-panel variability (Table 3 ). This correlation should enhance the field evaluation of the hygrothermal performance of wall and roof assemblies that use OSB.Nonetheless, it would be helpful to have further verification that OSB from different locations can be accounted for in a generic OSB correlation without introducing significant error. The inherent variability of wood and different OSB manufacturing techniques will always mean that moisture pin methods are less accurate than direct gravimetric measurement for determination of moisture content. Yet the practical advantages of moisture pins for field investigation will drive continued efforts to improve this method.

\section{Conclusion}

Samples of commercial OSB from mills in three different regions in North America were conditioned to a range of moisture contents in equilibrium with relative humidity levels from $35 \% \mathrm{RH}$ to $95 \% \mathrm{RH}$ at room temperature. These samples were then subjected to a wide range of temperatures $(-17$ to $70^{\circ} \mathrm{C}$ ) at which the resistance between a set of moisture pins was measured. The samples were then oven-dried to obtain the gravimetric moisture content and a correlation was developed to allow prediction of the moisture content given the resistance and temperature readings. The proposed correlation (eq. 2) is more concise and has a better root-mean-square-error than other commonly used correlations. It allows for a more accurate determination of moisture content in OSB and covers a wide temperature range making it useful for field investigations.

\section{Acknowledgments}


This manuscript was improved by comments from Marshall Begel and Laura Hasburgh of the USDA Forest Products Laboratory (FPL), and anonymous reviewers. The writers gratefully acknowledge the help of many FPL colleagues during the course of this investigation, including Robert Munson, Alex Wiedenhoeft, and Laurice Spinelli.

Research was funded by the Forest Products Laboratory of the U.S. Forest Service. This research was performed by U.S. government employees on official time and is therefore in the public domain and not subject to copyright.

\section{References}

[1] Zerbe, J.I., Z. Cai, and G.B. Harpole. An Evolutionary History of Oriented Strandboard (OSB). Forest Products Laboratory, Madison, WI. FPL-GTR-236;2015.

[2] Carll, C, A. Wiedenhoeft. Moisture-related properties of wood and the effects of moisture on wood and wood products. In: Moisture control in buildings: the key factor in mold preventions. ASTM International, MNL $182^{\text {nd }}$ ed.;2009.

[3] Haughton, L., and C. Murphy. "Moisture Exchange": Performance of OSB and Plywood Structural Panels. Interface, June 2003.

[4] Cautley, D. Comparative measured moisture performance of wood-frame walls. Proceedings, Woodframe housing durability and disaster issues. Madison, WI: Forest Products Society: 201-209; 2004.

[5] Carll, C., A. TenWolde, and R. Munson. Moisture Performance of a Contemporary Wood-Frame House Operated at Design Indoor Humidity Levels, Proceedings, Thermal Performance of Exterior Envelopes of Whole Buildings X, Clearwater Beach, FL, Dec. 2-7, 2007. ASHRAE, Atlanta, GA. ORNL 07Go1409/aas

[6] S. D. Gatland II, A. N. Karagiozis, C. Murray, and K. Ueno, The Hygrothermal Performance of WoodFramed Wall Systems Using a Relative Humidity-Dependent Vapor Retarder in the Pacific Northwest, Proceedings, Thermal Performance of the Exterior Envelopes of Whole Buildings X International Conference, Clearwater Beach, FL, USA, 2007.

[7] Tichy, R.; Murray, C. Developing Innovative Wall Systems that Improve Hygrothermal Performance of Residential Buildings. Final Report to U.S. Department of Energy; 2007.

[8] Wilkinson, J., Ueno, K., De Rose, D., Straube, J.F., Fugler, D. Understanding vapour permeance and condensation in wall assemblies, Proceedings of the 11th Canadian Conference on Building Science and Technology, Banff, Alberta; 2007.

[9] Schumacher, C.J. Hygrothermal Performance of Insulated, Sloped, Wood-Framed Roof Assemblies. Master's Thesis, Department of Civil Engineering, University of Waterloo, Ontario, Canada; 2008. 
[10] Armstrong. M.M., Maref. W., Rousseau. M., Lei. W. and Nicholls. M. A field monitoring study of interstitial condensation in wood-frame walls in cold climate, Proceedings of the 12th Canadian Conference on Building Science and Technology, Montréal, Quebec, May 6-8, 2009.

[11] S. C. Drumheller and C. G. Carll, Effect of cladding systems on moisture performance of woodframed walls in a mixed-humid climate, Proceedings, Thermal Performance of the Exterior Envelopes of Whole Buildings XI International Conference, Clearwater Beach, FL, USA, 2010.

[12] Yuan, S.; Karagiozis, A.N. The Hygrothermal Performance of Wood-Framed Wall Systems Using Spray Polyurethane Foam Insulations and a Smart Vapor Retarder in the Pacific Northwest. Proceedings, Thermal Performance of the Exterior Envelopes of Whole Buildings XI International Conference, Clearwater Beach, FL, USA, 5-9 December 2010.

[13] Weston, T.A.; Minnich, L.C. Moisture measurements and condensation potential in wood frame walls in a hot-humid climate. J. Test. Eval. 2011, 39, 395-409.

[14] Arena, L.B.; Owens, D.; Mantha, P. Measured Performance of an R-40 Double-Stud Wall in Climate Zone 5a. Proceedings, Thermal Performance of the Exterior Envelopes of Whole Buildings XII International Conference, Clearwater Beach, FL, USA, 1-5 December 2013.

[15] Grin A, Smegal J, Lstiburek J. Application of spray foam insulation under plywood and oriented strand board roof sheathing. Building America Report 1312; Building Science Corporation, Somerville, MA, USA;2013.

[16] Parsons, G.; Lieburn, B. Comparative Energy and Wall Performance of Twelve Residential Houses Constructed in a Cold Climate. Proceedings, Thermal Performance of the Exterior Envelopes of Whole Buildings XII International Conference, Clearwater Beach, FL, USA, 1-5 December 2013.

[17] Smegal, J.; Lstiburek, J.; Straube, J.; Grin, A. Moisture-Related Durability of Walls with Exterior Insulation in the Pacific Northwest. Proceedings, Thermal Performance of the Exterior Envelopes of Whole Buildings XII International Conference, Clearwater Beach, FL, USA, 1-5 December 2013.

[18] Craven, C.; Garber-Slaght, R. Exterior insulation envelope retrofits in cold climates: Implications for moisture control. HVAC\&R Res. 2014, 20, 384-394.

[19] Fox, M.; Straube, J.; Ge, H.; Trainor, T. Field Test of Hygrothermal Performance of Highly Insulated Wall Assemblies. Proceedings of the 14th Canadian Conference on Building Science and Technology, Toronto, Canada, 28-30 October 2014; pp. 101-110.

[20] HIRL. Moisture Performance of Walls in Energy Efficient Homes. Home Innovation Research Labs, Upper Marlboro, MD. Report 5932.001_08142014; 2014.

[21] Glass, S.V., V. Kochkin, S.C. Drumheller, and L. Barta. Moisture Performance of Energy -Efficient and Conventional Wood-Frame Wall Assemblies in a Mixed-Humid Climate. Buildings 2015(5):759-782. DOI: 10.3390/buildings5030759 
[22] Ueno, K. Monitoring of Double-Stud Wall Moisture Conditions in the Northeast; Building America Report 1501; Building Science Corporation: Westford, MA, USA, 2015.

[23] K. Ueno and J. W. Lstiburek, "Field Testing Unvented Roofs with Asphalt Shingles in Cold and HotHumid Climates," Building America Report 1409, Building Science Corporation, Westford, MA, USA, 2015.

[24] Glass, S.V.; Yeh, B.; Herzog, B.J. Effects of Exterior Insulation on Moisture Performance of WoodFrame Walls in the Pacific Northwest: Measurements and Hygrothermal Modeling. Proceedings of the 3rd Residential Building Design \& Construction Conference, March 2-3, 2016, University Park, PA, USA: 292-311.

[25] Vereecken E, Roels S. Review of mould prediction models and their influence on mould risk evaluation. Building and Environment. 2012;51:296-310.

[26] Thelandersson S, Isaksson T. Mould resistance design (MRD) model for evaluation of risk for microbial growth under varying climate conditions. Building and Environment. 2013;65:18-25.

[27] Pietrzyk K. A systemic approach to moisture problems in buildings for mould safety modelling. Building and Environment. 2015;86:50-60.

[28] Viitanen H, Vinha J, Salminen K, Ojanen T, Peuhkuri R, Paajanen L, et al. Moisture and Biodeterioration Risk of Building Materials and Structures. Journal of Building Physics. 2010;33:201-24.

[29] Viitanen H, Toratti T, Makkonen L, Peuhkuri R, Ojanen T, Ruokolainen L, et al. Towards modelling of decay risk of wooden materials. European Journal of Wood and Wood Products. 2010;68:303-13.

[30] Saito H, Fukuda K, Sawachi T. Integration model of hygrothermal analysis with decay process for durability assessment of building envelopes. Building Simulation. 2012;5:315-24.

[31] Isaksson T, Brischke C, Thelandersson S. Development of decay performance models for outdoor timber structures. Materials and Structures. 2013;46:1209-25.

[32] Brischke C, Meyer-Veltrup L. Modelling timber decay caused by brown rot fungi. Materials and Structures. 2016;49:3281-91.

[33] Zelinka SL, Derome D, Glass SV. Combining hygrothermal and corrosion models to predict corrosion of metal fasteners embedded in wood. Building and Environment. 2011;46:2060-8.

[34] Zelinka SL, Glass SV, Derome D. The effect of moisture content on the corrosion of fasteners embedded in wood subjected to alkaline copper quaternary treatment. Corrosion Science. 2014;83:6774.

[35] Zelinka SL, Glass SV, Boardman CR, Derome D. Comparison of the corrosion of fasteners embedded in wood measured in outdoor exposure with the predictions from a combined hygrothermal-corrosion model. Corrosion Science. 2016;102:178-85. 
[36]P.I. Morris, Understanding Biodeterioration of Wood in Structures. Forinteck Canada Corp., British Columbia Building Envelope Council. http://cwc.ca/wp-content/uploads/aboutdecaybiodeterioration.pdf (accessed 2016.11.15).

[37] C.A. Clausen, Wood Handbook, Ch. 14: Biodeterioration of Wood. Forest Products Laboratory, Madison, WI, 2010. FPL-GTR-190. http://www.fpl.fs.fed.us/documnts/fplgtr/fplgtr190/chapter_14.pdf (accessed 2016.11.15).

[38] Carll, C.G.; Highley, T.L. 1999. Decay of wood and wood-based products above ground in buildings. Journal of Testing and Evaluation 1999;27(2):150-158

[39]Arena, L., and P. Mantha. Moisture Research - Optimizing Wall Assemblies. US DOE, Building Technologies Program, Report DOE/GO-102013-3813; 2013 DOI: 10.2172/1079731

[40]Cornick, S.M., W. Maref and F. Tariku. Verification and validation: establishing confidence in hygrothermal tools. National Research Council of Canada. Research Report IRC-RR-278; 2009.

[41] Karagiozis, A. Application of Advanced Tools to Develop Energy Efficient Building Envelopes that Are Durable. Proceedings, Performance of Exterior Envelopes of Whole Buildings IX International Conference, Clearwater Beach, FL, USA, 5-10 December 2004.

[42] Finch, G.; Straube, J. Ventilated Wall Claddings: Review, Field Performance, and Hygrothermal Modeling. Proceedings, Thermal Performance of the Exterior Envelopes of Whole Buildings $X$ International Conference, Clearwater Beach, FL, USA, 2-7 December 2007.

[43] Tariku, F.; Cornick, S.M.; Lacasse, M.A. Simulation of Wind-Driven Rain Penetration Effects on the Performance of a Stucco-Clad Wall. Proceedings, Thermal Performance of the Exterior Envelopes of Whole Buildings X International Conference, Clearwater Beach, FL, USA, 2007.

[44]Straube J, Smegal J. Building America Special Research Project: High-R Walls Case Study Analysis. Research Report BA-0903, Building Science Corporation, Somerville, MA, USA, 2009.

[45] Pazera, M.; Salonvaara, M. Drying characteristics of spray-applied cellulose fiber insulation. J. Test. Eval. 2011, 39, 219-229.

[46] Pallin, S.; Kehrer, M.; Miller, W.A. A Hygrothermal Risk Analysis Applied to Residential Unvented Attics. Proceedings, Thermal Performance of the Exterior Envelopes of Whole Buildings XII International Conference, Clearwater Beach, FL, USA, 1-5 December 2013.

[47] Salonvaara, M.; Karagiozis, A.; Desjarlais, A. Moisture Performance of Sealed Attics in Climate Zones 1 to 4. Proceedings, Thermal Performance of the Exterior Envelopes of Whole Buildings XII International Conference, Clearwater Beach, FL, USA, 1-5 December 2013.

[48] Saber, H.H.; Maref, W. Risk of Condensation and Mould Growth in Wood-Frame Wall Systems with Different Exterior Insulations. Proceedings of Building Enclosure Science \& Technology Conf. (BEST4), April 12-15, 2015, Kansas City, Missouri, USA. 
[49] S.V. Glass, A. TenWolde, Review of in-service moisture and temperature conditions in wood-frame buildings, Forest Products Laboratory, Madison, WI 2007. FPL-GTR-174.

[50] J. Langmans, R Klein, S. Roels, Hygrothermal risks of using exterior air barrier systems for highly insulated light weight walls: A laboratory investigation, Building and Environment 56 (2012) 192-202.

[51] Onysko, D.M., C. Schumacher, and P. Garrahan. Field Measurements of Moisture in Building Materials and Assemblies: Pitfalls and Error Assessment. In Proceedings of BEST 1 conference June 1012, 2008, Minneapolis, MN.

[52] Straube, J., D. Onysko, and C. Schumacher. Methodology and Design of Field Experiments for Monitoring Hygrothermal Performance of Wood Frame Enclosures. Journal of Thermal Env. \& Bldg. Sci. 2002;26(2): 123-151. DOI: 10.1106/109719602028098

[53] James, W.L. Electric Moisture Meters for Wood. Forest Products Laboratory, Madison, WI. FPL-08; 1963.

[54] James, W.L. Electric Moisture Meters for Wood. Forest Products Laboratory, Madison, WI. FPL-GTR6; 1988.

[55] Pfaff, F. and P. Garrahan. New temperature correction factors for the portable resistance-type moisture meter. Forest Products Journal 1986;36(3):28-30.

[56] Garrahan, P. Moisture meter correction factors. In Proceeds of a Seminar on In-Grade Testing of Structural Lumber, Madison, WI, April 25-26, 1988. Madison WI: Forest Products Laboratory, US Forest Service.

[57]James, W. Effect of temperature on readings of electric moisture meters. Forest Products Journal 1968;18(10):23-31.

[58] Boardman, C.R., S.V. Glass and C.G. Carll. Moisture Meter Calibrations for Untreated and ACQTreated Southern Yellow Pine Lumber and Plywood. Journal of Testing and Evaluation 2012;40(1). JTE103895.

[59] Maref, W. M.A. Lacasse, and D.G. Booth. Experimental assessment of hygrothermal properties of wood-frame wall assemblies -- moisture content calibration curve for OSB using moisture pins. Journal of ASTM International 2010; Vol. 7, No. 1.

[60] Zelinka, S., S.V. Glass, and D.S. Stone. A percolation model for electrical conduction in wood with implications for wood-water relations. Wood and Fiber Science 2008;40(4):544-552.

[61] Hummel, R.E, Electrical Properties of Polymers, Ceramics, Dielectrics, and Amorphous Materials, Ch. 9 in Electronic Properties of Materials, Springer-Verlag; 2001.

[62] Aziz, S., and Z. G. Z. Abidin. Electrical Conduction Mechanism in Solid Polymer Electrolytes: New Concepts to Arrhenius Equation. Journal of Soft Matter (2013). http://dx.doi.org/10.1155/2013/323868 
[63] Kasap, S.D. Principles of electronic materials and devices ( $3^{\text {rd }}$ ed). Chapter 2. Electrical and Thermal Conduction in Solids. McGraw-Hill; 2015

[64]ASTM D4442. Standard test methods for direct moisture content measurement of wood and woodbased materials. West Conshohocken, PA: American Standard for Testing and Materials; 2015.

[65]SAS. Cary, NC: SAS Institute, Inc.; 2013. http://support.sas.com/documentation/94/. (November 16, 2016).

[66]R Core Team. 2016. R: A language and environment for statistical computing. R Foundation for Statistical Computing, Vienna, Austria; 2016. https://www.R-project.org/.

[67]Zylkowski SC. Dimensional Stability of Structural-Use Panels, Report No. R\&D86L-43. Tacoma, WA: American Plywood Association; 1986.

[68] Richards RF, Burch DM, Thomas WC. Water vapor sorption measurements of common building materials. ASHRAE Transactions. 1992;98:475-83.

[69] Sekino N, Suematsu A, Kohrai H, Yasui E. Measurements of sorption isotherms of selected commercial wood-based panels and predictions of moisture content changes in service. Mokuzai Gakkaishi. 1999;45:237-43.

[70] Wu QL, Ren YK. Characterization of sorption behavior of oriented strandboard under long-term cyclic humidity exposure condition. Wood and Fiber Science. 2000;32:404-18.

[71] Kumaran MK, Lackey JC, Normandin N, Tariku F, van Reenen D. A thermal and moisture transport property database for common building and insulating materials: Final report from ASHRAE Research Project 1018-RP. Atlanta, GA: American Society of Heating, Refrigerating and Air-Conditioning Engineers, Inc.; 2002.

[72] Kumaran MK, Lackey JC, Normandin N, Tariku F, Van Reenen D. Variations in the hygrothermal properties of several wood-based building products. In: Carmeliet J., Hens H., Vermeir G., editors. Research in Building Physics: Proceedings of the 2nd International Conference on Building Physics. Antwerpen, Belgium: Swets \& Zeitlinger B.V.; 2003. p. 35-42.

[73] Karagiozis A, Wilkes K. Hygrothermal properties of selected materials. Report 2, ASHRAE Research Project 1091, Development of design strategies for rainscreen and sheathing membrane performance in wood frame walls. Atlanta, GA, USA: American Society of Heating, Refrigerating and Air-Conditioning Engineers, Inc.; 2004.

[74] Ojanen T, Ahonen J, Simonson CJ. Moisture performance characteristics of OSB and spruce plywood exterior sheathing products. In: Fazio P., Ge H., Rao J., Desmarais G., editors. Research in Building Physics and Building Engineering: Proceedings of the Third International Building Physics Conference. Montreal, Canada: Taylor \& Francis; 2006. p. 97-105.

[75] Hartley ID, Wang SQ, Zhang Y. Water vapor sorption isotherm modeling of commercial oriented strand panel based on species groups and resin type. Building and Environment. 2007;42:3655-9. 


\section{Appendix}

Table A.1 Primary data set

\begin{tabular}{|c|c|c|c|c|c|c|c|c|}
\hline \multirow[b]{2}{*}{ Sample } & \multirow[b]{2}{*}{ MC (\%) } & \multirow{2}{*}{$\begin{array}{l}\mathrm{MC}(\%) \text { at } \\
70^{\circ} \mathrm{C}\end{array}$} & \multicolumn{6}{|c|}{ 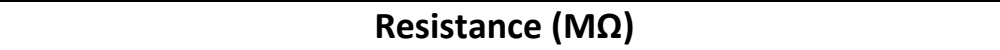 } \\
\hline & & & $-17^{\circ} \mathrm{C}$ & $-5^{\circ} \mathrm{C}$ & $5{ }^{\circ} \mathrm{C}$ & $23^{\circ} \mathrm{C}$ & $40^{\circ} \mathrm{C}$ & $70^{\circ} \mathrm{C}$ \\
\hline 1 & 17.9 & 17.4 & 143 & 36.5 & 14.0 & 3.43 & 1.19 & 0.270 \\
\hline 2 & 19.2 & 18.6 & 48.6 & 13.8 & 5.71 & 1.46 & 0.553 & 0.116 \\
\hline 3 & 17.5 & 16.9 & 75.5 & 20.7 & 8.04 & 1.93 & 0.686 & 0.150 \\
\hline 4 & 17.8 & 17.2 & 42.9 & 12.4 & 4.95 & 1.35 & 0.500 & 0.120 \\
\hline 5 & 19.3 & 18.6 & 24.3 & 7.40 & 3.22 & 0.884 & 0.362 & 0.0819 \\
\hline 6 & 17.6 & 17.0 & 72.5 & 20.6 & 7.78 & 1.89 & 0.694 & 0.144 \\
\hline 7 & 18.0 & 17.3 & 64.9 & 19.1 & 7.23 & 1.75 & 0.623 & 0.140 \\
\hline 8 & 18.1 & 17.4 & 41.7 & 12.3 & 4.94 & 1.26 & 0.472 & 0.111 \\
\hline 9 & 17.2 & 16.7 & 34.8 & 10.0 & 3.91 & 1.01 & 0.414 & 0.0942 \\
\hline 10 & 17.4 & 16.9 & 66.6 & 19.4 & 7.24 & 1.81 & 0.666 & 0.127 \\
\hline 11 & 18.1 & 17.5 & 95.0 & 25.8 & 9.59 & 2.53 & 0.953 & 0.191 \\
\hline 12 & 18.3 & 17.7 & 37.6 & 10.8 & 4.39 & 1.22 & 0.469 & 0.109 \\
\hline 13 & 18.2 & 17.6 & 47.2 & 14.1 & 5.66 & 1.58 & 0.627 & 0.147 \\
\hline 14 & 17.5 & 16.9 & 57.6 & 16.5 & 6.47 & 1.60 & 0.557 & 0.125 \\
\hline 15 & 17.6 & 17.0 & 56.1 & 16.2 & 6.65 & 1.71 & 0.632 & 0.119 \\
\hline 16 & 7.0 & 7.0 & & 26000 & 10900 & 6280 & 1360 & 78.9 \\
\hline 17 & 6.9 & 6.9 & & 32000 & 16400 & 8050 & 1760 & 99.4 \\
\hline 18 & 6.8 & 6.8 & & 22400 & 9070 & 4500 & 981 & 37.6 \\
\hline 19 & 7.0 & 7.0 & & 26000 & 10800 & 4230 & 740 & 36.5 \\
\hline 20 & 7.0 & 7.0 & & 16500 & 10300 & 3130 & 522 & 20.1 \\
\hline 21 & 7.0 & 7.0 & & 24500 & 15700 & 5680 & 972 & 44.7 \\
\hline 22 & 6.9 & 6.9 & & 20300 & 10100 & 3610 & 903 & 31.1 \\
\hline 23 & 7.0 & 7.0 & & 36500 & 12800 & 2730 & 755 & 26.5 \\
\hline 24 & 6.9 & 6.9 & & 29400 & 13400 & 5400 & 1480 & 84.4 \\
\hline 25 & 7.0 & 7.0 & & 23300 & 15400 & 9740 & 2140 & 92.5 \\
\hline 26 & 6.8 & 6.8 & & 23500 & 17500 & 5640 & 1080 & 52.0 \\
\hline 27 & 7.6 & 7.6 & & 26000 & 13500 & 3180 & 660 & 26.9 \\
\hline 28 & 6.7 & 6.7 & & 16700 & 14200 & 9440 & 1740 & 58.0 \\
\hline 29 & 7.0 & 7.0 & & 25200 & 14000 & 7190 & 1290 & 76.0 \\
\hline 30 & 6.7 & 6.7 & & 21400 & 12300 & 5100 & 1240 & 51.4 \\
\hline 31 & 8.7 & 8.7 & 9380 & 7140 & 3110 & 530 & 72.0 & 5.12 \\
\hline 32 & 8.6 & 8.6 & 16000 & 9740 & 3710 & 814 & 108 & 7.49 \\
\hline 33 & 8.7 & 8.7 & 14500 & 11000 & 3550 & 679 & 95.0 & 6.73 \\
\hline 34 & 8.7 & 8.7 & 17500 & 8660 & 3220 & 651 & 85.8 & 6.10 \\
\hline
\end{tabular}




\begin{tabular}{|c|c|c|c|c|c|c|c|c|}
\hline 35 & 8.9 & 8.9 & 15500 & 6360 & 2460 & 325 & 56.3 & 3.86 \\
\hline 36 & 9.3 & 9.3 & 17200 & 8460 & 3230 & 741 & 114 & 8.18 \\
\hline 37 & 9.4 & 9.4 & 10300 & 6440 & 2180 & 449 & 68.1 & 5.41 \\
\hline 38 & 8.7 & 8.7 & 17400 & 7240 & 2790 & 434 & 69.4 & 5.75 \\
\hline 39 & 9.2 & 9.2 & 16600 & 9280 & 2590 & 501 & 94.6 & 6.30 \\
\hline 40 & 8.6 & 8.6 & 17700 & 9210 & 2670 & 606 & 101 & 6.53 \\
\hline 41 & 9.3 & 9.3 & 15100 & 7900 & 2890 & 409 & 66.0 & 5.08 \\
\hline 42 & 8.8 & 8.8 & 12200 & 15600 & 3120 & 739 & 110 & 7.66 \\
\hline 43 & 8.7 & 8.7 & 22200 & 9710 & 4630 & 908 & 183 & 11.4 \\
\hline 44 & 9.6 & 9.6 & 15100 & 7010 & 2850 & 614 & 103 & 7.92 \\
\hline 45 & 8.9 & 8.9 & 14700 & 6240 & 2520 & 472 & 91.6 & 6.49 \\
\hline 46 & 4.5 & 4.5 & & & 13600 & 4850 & 3770 & 321 \\
\hline 47 & 4.8 & 4.8 & & & 14700 & 10800 & 4170 & 251 \\
\hline 48 & 5.2 & 5.2 & & & 12700 & 7310 & 3160 & 191 \\
\hline 49 & 4.8 & 4.8 & & & 16700 & 11500 & 3610 & 260 \\
\hline 50 & 4.5 & 4.5 & & & 14200 & 9810 & 3870 & 287 \\
\hline 51 & 4.4 & 4.4 & & & 16600 & 5830 & 3960 & 301 \\
\hline 52 & 4.6 & 4.6 & & & 16100 & 8910 & 3090 & 232 \\
\hline 53 & 4.5 & 4.5 & & & 20600 & 9170 & 3770 & 247 \\
\hline 54 & 4.4 & 4.4 & & & 14600 & 5970 & 3890 & 280 \\
\hline 55 & 4.5 & 4.5 & & & 16700 & 6650 & 3810 & 284 \\
\hline 56 & 4.4 & 4.4 & & & 14300 & 7090 & 3900 & 295 \\
\hline 57 & 4.4 & 4.4 & & & 26700 & 9730 & 3250 & 267 \\
\hline 58 & 4.4 & 4.4 & & & 24600 & 8090 & 6010 & 299 \\
\hline 59 & 4.5 & 4.5 & & & 16300 & 8880 & 3800 & 242 \\
\hline 60 & 4.4 & 4.4 & & & 16400 & 4470 & 3960 & 313 \\
\hline 61 & 11.8 & 11.4 & 3840 & 1410 & 429 & 63.0 & 12.9 & 1.72 \\
\hline 62 & 11.7 & 11.4 & 3960 & 1180 & 354 & 51.1 & 9.59 & 1.19 \\
\hline 63 & 11.9 & 11.7 & 2580 & 894 & 280 & 42.8 & 9.59 & 1.27 \\
\hline 64 & 11.8 & 11.4 & 3660 & 1160 & 362 & 53.1 & 10.5 & 1.50 \\
\hline 65 & 11.5 & 11.2 & 3060 & 828 & 269 & 39.0 & 7.72 & 1.08 \\
\hline 66 & 11.8 & 11.5 & 3330 & 995 & 298 & 41.8 & 7.93 & 1.09 \\
\hline 67 & 11.7 & 11.3 & 2600 & 687 & 210 & 30.9 & 6.14 & 0.831 \\
\hline 68 & 11.5 & 11.2 & 2960 & 629 & 189 & 28.1 & 5.50 & 0.832 \\
\hline 69 & 11.7 & 11.3 & 3600 & 1120 & 342 & 48.8 & 9.50 & 1.18 \\
\hline 70 & 11.4 & 11.2 & 2590 & 682 & 207 & 30.9 & 6.97 & 0.924 \\
\hline 71 & 11.4 & 11.0 & 2910 & 946 & 293 & 44.9 & 9.12 & 1.25 \\
\hline 72 & 12.3 & 11.9 & 2980 & 738 & 238 & 38.0 & 7.97 & 1.10 \\
\hline 73 & 11.9 & 11.6 & 3570 & 768 & 244 & 37.4 & 8.29 & 1.14 \\
\hline 74 & 11.7 & 11.4 & 3230 & 807 & 259 & 39.8 & 8.16 & 1.13 \\
\hline 75 & 11.8 & 11.5 & 2700 & 849 & 264 & 40.0 & 8.42 & 1.33 \\
\hline 76 & 21.6 & 21.2 & 15.7 & 5.04 & 2.09 & 0.601 & 0.259 & 0.0856 \\
\hline 77 & 21.3 & 20.3 & 10.8 & 3.42 & 1.48 & 0.445 & 0.178 & 0.0597 \\
\hline
\end{tabular}




$\begin{array}{lllllllll}78 & 22.1 & 21.0 & 6.84 & 2.26 & 1.02 & 0.337 & 0.140 & 0.0526 \\ 79 & 22.4 & 21.3 & 6.77 & 2.19 & 0.973 & 0.338 & 0.141 & 0.0516 \\ 80 & 22.5 & 21.3 & 7.96 & 2.65 & 1.21 & 0.432 & 0.181 & 0.0619 \\ 81 & 21.9 & 20.6 & 10.5 & 3.36 & 1.46 & 0.481 & 0.199 & 0.0712 \\ 82 & 21.5 & 20.6 & 13.3 & 4.11 & 1.80 & 0.536 & 0.260 & 0.0779 \\ 83 & 22.4 & 21.3 & 5.22 & 1.74 & 0.869 & 0.328 & 0.132 & 0.0483 \\ 84 & 22.4 & 21.4 & 8.29 & 2.58 & 1.08 & 0.383 & 0.165 & 0.0586 \\ 85 & 21.5 & 20.6 & 13.7 & 4.29 & 1.80 & 0.556 & 0.229 & 0.0774 \\ 86 & 21.7 & 20.8 & 8.62 & 2.84 & 1.24 & 0.417 & 0.176 & 0.0633 \\ 87 & 21.8 & 20.5 & 20.2 & 6.47 & 2.67 & 0.878 & 0.309 & 0.103 \\ 88 & 22.2 & 21.3 & 10.3 & 3.26 & 1.39 & 0.478 & 0.191 & 0.0689 \\ 89 & 21.7 & 20.8 & 7.96 & 2.57 & 1.10 & 0.366 & 0.148 & 0.0561 \\ 90 & 22.1 & 20.9 & 13.6 & 4.30 & 1.90 & 0.601 & 0.242 & 0.0861 \\ \text { W1 } & 8.2 & 8.2 & 19800 & 11200 & 9690 & 1530 & 268 & 19.1 \\ \text { W2 } & 8.4 & 8.4 & 13400 & 6230 & 2390 & 403 & 77.9 & 8.22 \\ \text { W3 } & 8.6 & 8.6 & 19000 & 18800 & 7580 & 1500 & 324 & 26.7 \\ \text { W4 } & 9.0 & 9.0 & 14800 & 8010 & 2550 & 486 & 97.9 & 7.40 \\ \text { W5 } & 8.7 & 8.7 & 13300 & 8570 & 3350 & 635 & 125 & 9.80 \\ \text { W6 } & 9.5 & 9.5 & 17000 & 14200 & 3970 & 802 & 164 & 12.7 \\ \text { W7 } & 20.3 & 19.5 & 14.0 & 4.40 & 1.97 & 0.606 & 0.268 & 0.0672 \\ \text { W8 } & 20.5 & 19.7 & 13.3 & 4.22 & 1.83 & 0.593 & 0.278 & 0.0711 \\ \text { W9 } & 19.7 & 19.0 & 26.7 & 8.26 & 3.67 & 1.04 & 0.474 & 0.102 \\ \text { W10 } & 19.2 & 18.5 & 30.4 & 9.00 & 3.87 & 1.06 & 0.465 & 0.102 \\ \text { W11 } & 19.2 & 18.3 & 66.6 & 20.4 & 8.36 & 2.23 & 0.878 & 0.179 \\ \text { W12 } & 19.9 & 19.2 & 43.1 & 13.6 & 5.58 & 1.66 & 0.665 & 0.141\end{array}$

Table A.2 Supplemental data set

\begin{tabular}{|c|c|c|c|c|c|c|}
\hline \multirow[b]{2}{*}{ Sample } & \multirow[b]{2}{*}{ MC (\%) } & \multicolumn{5}{|c|}{ Resistance (M $\Omega$ ) } \\
\hline & & $-17^{\circ} \mathrm{C}$ & $0^{\circ} \mathrm{C}$ & $20^{\circ} \mathrm{C}$ & $40^{\circ} \mathrm{C}$ & $60^{\circ} \mathrm{C}$ \\
\hline $\mathrm{H} 1$ & 12.7 & 3630 & 504 & 65.7 & 9.47 & 2.74 \\
\hline $\mathrm{H} 2$ & 12.8 & 1660 & 212 & 28.8 & 4.77 & 1.38 \\
\hline H3 & 13.1 & 1690 & 219 & 31.2 & 5.65 & 1.62 \\
\hline $\mathrm{H} 4$ & 12.5 & 2270 & 303 & 40.5 & 6.09 & 1.82 \\
\hline H5 & 12.6 & 1640 & 212 & 28.9 & 4.94 & 1.43 \\
\hline $\mathrm{H} 6$ & 12.6 & 2580 & 322 & 42.7 & 6.69 & 1.90 \\
\hline $\mathrm{H} 7$ & 12.9 & 1500 & 199 & 27.7 & 4.70 & 1.40 \\
\hline H8 & 12.8 & 1740 & 217 & 29.3 & 4.79 & 1.42 \\
\hline H9 & 13.1 & 1230 & 161 & 23.0 & 3.79 & 1.19 \\
\hline $\mathrm{H} 10$ & 13.2 & 1820 & 213 & 28.1 & 4.91 & 1.41 \\
\hline
\end{tabular}


Table A.3 Secondary data set

\begin{tabular}{|c|c|c|c|c|c|c|c|c|}
\hline \multirow[b]{2}{*}{ Sample } & \multirow[b]{2}{*}{ MC (\%) } & \multicolumn{7}{|c|}{ Resistance (M $\Omega$ ) } \\
\hline & & $-17^{\circ} \mathrm{C}$ & $-5^{\circ} \mathrm{C}$ & $5^{\circ} \mathrm{C}$ & $10^{\circ} \mathrm{C}$ & $23^{\circ} \mathrm{C}$ & $40^{\circ} \mathrm{C}$ & $60^{\circ} \mathrm{C}$ \\
\hline BC 1 & 15.7 & 226 & 51.2 & 19.9 & 12.5 & 3.18 & 1.27 & 0.388 \\
\hline BC 2 & 15.2 & 384 & 93.5 & 31.8 & 20.6 & 4.85 & 1.97 & 0.572 \\
\hline $\mathrm{BC} 3$ & 15.2 & 480 & 116 & 40.9 & 26.6 & 7.05 & 2.54 & 0.759 \\
\hline BC 4 & 15.3 & 337 & 74.3 & 28.3 & 18.3 & 4.43 & 1.68 & 0.496 \\
\hline BC 5 & 15.8 & 402 & 97.7 & 33.6 & 21.8 & 5.41 & 2.14 & 0.652 \\
\hline BC 6 & 15.4 & 410 & 98.9 & 34.5 & 22.0 & 5.35 & 1.93 & 0.576 \\
\hline BC 7 & 6.7 & & & & 15400 & 7210 & 1880 & 267 \\
\hline BC 8 & 6.5 & & & & 17500 & 8410 & 1700 & 233 \\
\hline BC 9 & 6.9 & & & & 20000 & 8280 & 1600 & 202 \\
\hline BC 10 & 6.7 & & & & 17300 & 7700 & 1720 & 232 \\
\hline BC 11 & 6.9 & & & & 16300 & 6060 & 1430 & 186 \\
\hline BC 12 & 6.7 & & & & 17000 & 8140 & 1600 & 222 \\
\hline BC 13 & 8.7 & & & 6350 & 3560 & 1100 & 158 & 26.6 \\
\hline BC 14 & 8.6 & & & 7810 & 4820 & 1350 & 209 & 38.3 \\
\hline BC 15 & 8.8 & & & 6610 & 3420 & 1090 & 177 & 33.2 \\
\hline BC 16 & 8.5 & & & 7600 & 4010 & 1330 & 203 & 35.7 \\
\hline BC 17 & 8.6 & & & 7550 & 4050 & 1340 & 214 & 35.6 \\
\hline BC 18 & 8.5 & & & 8030 & 4900 & 1370 & 217 & 38.6 \\
\hline BC 19 & 5.3 & & & & & 13400 & 3380 & 560 \\
\hline BC 20 & 5.2 & & & & & 11700 & 3400 & 579 \\
\hline BC 21 & 5.4 & & & & & 11400 & 2760 & 441 \\
\hline BC 22 & 5.3 & & & & & 9080 & 3660 & 620 \\
\hline BC 23 & 5.3 & & & & & 13000 & 3450 & 562 \\
\hline BC 24 & 5.4 & & & & & 13200 & 2940 & 493 \\
\hline BC 25 & 10.8 & & 2660 & 852 & 487 & 153 & 29.3 & 6.18 \\
\hline BC 26 & 10.6 & & 3650 & 1200 & 665 & 218 & 38.8 & 8.08 \\
\hline BC 27 & 10.5 & & 2320 & 717 & 398 & 114 & 23.7 & 4.51 \\
\hline BC 28 & 10.6 & & 3120 & 1030 & 570 & 177 & 33.7 & 6.96 \\
\hline BC 29 & 10.8 & & 2590 & 788 & 440 & 136 & 25.6 & 5.39 \\
\hline BC 30 & 10.8 & & 3380 & 1100 & 608 & 194 & 35.4 & 7.77 \\
\hline BC 31 & 21.5 & 10.1 & 3.28 & 1.52 & 0.999 & 0.423 & 0.181 & 0.0894 \\
\hline BC 32 & 21.4 & 6.68 & 2.24 & 1.05 & 0.736 & 0.305 & 0.143 & 0.0682 \\
\hline BC 33 & 21.3 & 11.9 & 3.84 & 1.74 & 1.22 & 0.487 & 0.221 & 0.0983 \\
\hline BC 34 & 21.3 & 12.8 & 3.98 & 1.77 & 1.17 & 0.457 & 0.214 & 0.101 \\
\hline BC 35 & 21.4 & 9.63 & 3.32 & 1.47 & 0.982 & 0.420 & 0.188 & 0.0954 \\
\hline BC 36 & 21.5 & 14.4 & 4.52 & 2.05 & 1.45 & 0.556 & 0.247 & 0.112 \\
\hline TX 1 & 17.1 & 143 & 32.3 & 12.0 & 7.60 & 1.92 & 0.826 & 0.256 \\
\hline TX 2 & 17.6 & 126 & 30.0 & 11.6 & 7.34 & 2.06 & 0.852 & 0.281 \\
\hline TX 3 & 18.5 & 46.7 & 12.6 & 4.99 & 3.21 & 1.03 & 0.410 & 0.142 \\
\hline
\end{tabular}




\begin{tabular}{|c|c|c|c|c|c|c|c|c|}
\hline TX 4 & 18.1 & 107 & 26.0 & 10.0 & 6.35 & 2.02 & 0.745 & 0.251 \\
\hline TX 5 & 18.1 & 47.6 & 12.6 & 4.91 & 3.17 & 0.96 & 0.402 & 0.139 \\
\hline TX 6 & 18.1 & 55.5 & 14.5 & 5.67 & 3.59 & 1.12 & 0.471 & 0.161 \\
\hline TX 7 & 8.0 & & & & 5850 & 1670 & 257 & 26.9 \\
\hline TX 8 & 8.0 & & & & 7700 & 2250 & 353 & 35.8 \\
\hline TX 9 & 7.9 & & & & 7750 & 2210 & 323 & 28.9 \\
\hline TX 10 & 8.1 & & & & 6350 & 1530 & 244 & 24.2 \\
\hline TX 11 & 7.8 & & & & 9500 & 2630 & 405 & 36.4 \\
\hline TX 12 & 7.6 & & & & 8700 & 2420 & 377 & 30.7 \\
\hline TX 13 & 9.7 & & & 2300 & 1160 & 269 & 36.8 & 6.78 \\
\hline TX 14 & 9.6 & & & 2350 & 1200 & 262 & 34.1 & 6.05 \\
\hline TX 15 & 9.7 & & & 2090 & 1090 & 247 & 33.6 & 6.1 \\
\hline TX 16 & 9.7 & & & 2080 & 1060 & 246 & 35.7 & 6.6 \\
\hline TX 17 & 10.0 & & & 1780 & 939 & 212 & 30.1 & 5.6 \\
\hline TX 18 & 9.9 & & & 2050 & 1040 & 232 & 31.1 & 5.6 \\
\hline TX 19 & 6.3 & & & & & 8940 & 2080 & 304 \\
\hline TX 20 & 6.3 & & & & & 7330 & 1960 & 284 \\
\hline TX 21 & 6.5 & & & & & 8260 & 1810 & 230 \\
\hline TX 22 & 6.2 & & & & & 8270 & 1950 & 274 \\
\hline TX 23 & 6.2 & & & & & 8740 & 1920 & 254 \\
\hline TX 24 & 6.2 & & & & & 9480 & 2250 & 318 \\
\hline TX 25 & 12.1 & & 715 & 214 & 118 & 32.6 & 7.67 & 1.69 \\
\hline TX 26 & 12.1 & & 749 & 218 & 122 & 36.2 & 7.69 & 1.66 \\
\hline TX 27 & 12.2 & & 441 & 123 & 60.0 & 18.8 & 4.24 & 0.931 \\
\hline TX 28 & 12.1 & & 818 & 240 & 131 & 39.6 & 8.31 & 1.85 \\
\hline TX 29 & 12.2 & & 537 & 153 & 76.2 & 25.3 & 5.24 & 1.14 \\
\hline TX 30 & 12.0 & & 604 & 172 & 95.8 & 24.5 & 5.48 & 1.23 \\
\hline TX 31 & 23.1 & 9.43 & 2.96 & 1.32 & 1.02 & 0.409 & 0.171 & 0.0751 \\
\hline TX 32 & 23.2 & 6.91 & 2.16 & 0.974 & 0.757 & 0.302 & 0.131 & 0.0583 \\
\hline TX 33 & 23.3 & 7.38 & 2.38 & 1.10 & 0.881 & 0.348 & 0.150 & 0.0689 \\
\hline TX 34 & 23.3 & 4.28 & 1.38 & 0.637 & 0.491 & 0.209 & 0.0879 & 0.0418 \\
\hline TX 35 & 23.1 & 5.84 & 1.86 & 0.922 & 0.687 & 0.294 & 0.119 & 0.060 \\
\hline TX 36 & 23.1 & 4.64 & 1.47 & 0.699 & 0.528 & 0.229 & 0.0983 & 0.0466 \\
\hline
\end{tabular}

